\title{
1 Ion transport mechanisms for smoke inhalation injured airway epithelial barrier
}

\section{Jianjun Chang ${ }^{1,2}$, Zaixing Chen ${ }^{1 \&}$, Runzhen Zhao ${ }^{1}$, Hong-Guang $\mathrm{Nie}^{3 *}$, Hong-Long $\mathrm{Ji}^{1,4^{*}}$}

$3{ }^{1}$ Department of Cellular and Molecular Biology, University of Texas Health Science Center at Tyler, 11937 US Hwy 271 , Tyler Texas

$4 \quad 75708$, USA; ${ }^{2}$ Institute of Health Sciences, China Medical University, Shenyang 110122, Liaoning, China; ${ }^{3}$ Department of Stem Cells

5 and Regenerative Medicine, College of Basic Medical Science, China Medical University, Shenyang 110122 , Liaoning, China; ${ }^{4}$ Texas

6 Lung Injury Institute, University of Texas Health Science Center at Tyler, Tyler Texas 75708, USA

7 e-mail: jianjun_chang@yeah.net, zaixingchen@sina.com,runzhen.zhao@uthct.edu,hgnie@cmu.edu.cn,james.ji@uthct.edu

0 \&Present address: School of Pharmacy, China Medical University, Shenyang 110122, Liaoning, China

$2 \quad{ }^{*}$ Corresponding author.

Acknowledgments: This work was supported by the grants from the National Institute of Health (NIH HL134828), and the National 5 Natural Science Foundation of China (NSFC 81670010). 


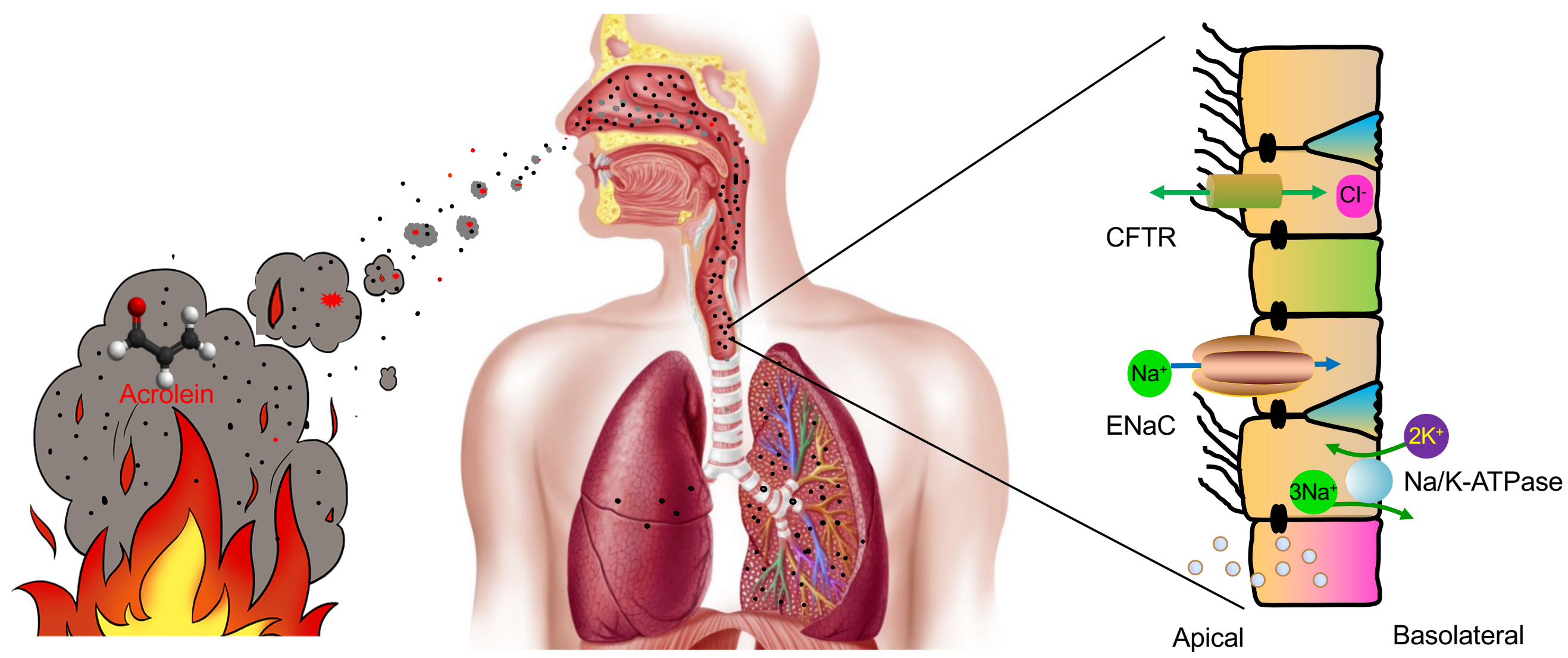


bioRxiv preprint doi: https://doi.org/10.1101/2020.03.25.007807; this version posted May 26, 2020. The copyright holder for this preprint (which was not certified by peer review) is the author/funder. All rights reserved. No reuse allowed without permission.

\section{Graphical Headlights}

- Thermal stress and acrolein are two essential determinants for smoke-inhalation injury, impairing airway epithelial barrier.

- Transcellular ion transport pathways via the ENaC, CFTR, and Na/K-ATPase are interrupted by both thermal stress and acrolein, one of the most potent smoke toxins.

- Heat and acrolein damage the integrity of the airway epithelium through suppressing and relocating the tight junctions. 
9 Abstract Smoke inhalation injury is the leading cause of death in firefighters and victims. Inhaled hot air and toxic smoke are the

0 predominant hazards to the respiratory epithelium. We aimed to analyze the effects of thermal stress and smoke aldehyde on the

1 permeability of the airway epithelial barrier. Transepithelial resistance ( $\left.\mathrm{R}_{\mathrm{TE}}\right)$ and short-circuit current ( $\mathrm{ISC}_{\mathrm{SC}}$ of mouse tracheal epithelial

2 monolayers were digitized by an Ussing chamber setup. Zonula occludens-1 tight junctions were visualized under confocal microscopy.

3 A cell viability test and fluorescein isothiocyanate-dextran assay were performed. Thermal stress $\left(40^{\circ} \mathrm{C}\right)$ decreased $\mathrm{R}_{\mathrm{TE}}$ in a two-phase

4 manner. Meanwhile, thermal stress increased IsC followed by its decline. $\mathrm{Na}^{+}$depletion, amiloride (an inhibitor for epithelial $\mathrm{Na}^{+}$

5 channels $[\mathrm{ENaCs}]$ ), ouabain (a blocker for $\mathrm{Na}^{+} / \mathrm{K}^{+}$-ATPase) and CFTRinh-172 (a blocker of cystic fibrosis transmembrane regulator

6 [CFTR]) altered the responses of RTE and Isc to thermal stress. Steady-state $40^{\circ} \mathrm{C}$ increased activity of ENaCs, $\mathrm{Na}^{+} / \mathrm{K}^{+}-\mathrm{ATPase}$, and

7 CFTR. Acrolein, one of the main oxidative unsaturated aldehydes in fire smoke, eliminated $\mathrm{R}_{\mathrm{TE}}$ and ISC. $\mathrm{Na}^{+}$depletion, amiloride,

8 ouabain, and CFTRinh-172 suppressed acrolein-sensitive ISC, but showed activating effects on acrolein-sensitive RTE. Thermal stress or

9 acrolein disrupted zonula occludens-1 tight junctions, increased fluorescein isothiocyanate-dextran permeability but did not cause cell

0 death or detachment. The synergistic effects of thermal stress and acrolein exacerbated the damage to monolayers. In conclusion, the

1 paracellular pathway mediated by the tight junctions and the transcellular pathway mediated by active and passive ion transport pathways

2 contribute to impairment of the airway epithelial barrier caused by thermal stress and acrolein.

3 Keywords: thermal stress; acrolein; tracheal epithelial monolayers; ion transport; tight junctions 


\section{Introduction}

Fire is a common disaster in urban and rural populations. Smoke is a complicated mixture of hot air, toxic chemicals, and suspended particles (Fitzgerald and Flood 2006). Inhalation of harmful smoke causes direct impairment of respiratory function and is the leading cause of fire-related death (Haponik 1993). Inhaled hot air and toxic chemicals in smoke from fire impair the respiratory tract and lungs.

The airway epithelium is the most important defense barrier in the respiratory tract (Wang et al. 2008). Approximately $80 \%$ of the cells are ciliated in the normal respiratory tract. These cells form a tight airway epithelial layer, which can effectively prevent various external attacks (Hou et al. 2019). Destruction of the integrity of the airway epithelial barrier can be an important indicator of occurrence and the development of many respiratory diseases (Wang et al. 2007). Under pathological conditions, the integrity of the airway epithelial barrier is disrupted and its permeability is increased. Permeability of a tight airway epithelium is determined by paracellular and transcellular pathways. Paracellular pathway is predominantly regulated by tight junctions and lateral intercellular space. Transcellular permeability is predominantly controlled by active and passive ion transport pathways. Apical epithelial $\mathrm{Na}^{+}$channels (ENaCs) and cystic fibrosis transmembrane regulator (CFTR), as well as basolateral $\mathrm{Na}^{+} / \mathrm{K}^{+}$-ATPase, are mainly responsible for $\mathrm{Na}^{+} / \mathrm{Cl}^{-}$ transport in the respiratory epithelium (Chang et al. 2018; Wang et al. 2007). In respiratory epithelium, passive ion transport mediated by ENaCs is an important determinant of transcellular permeability, and active $\mathrm{Na}^{+} / \mathrm{K}^{+}$-ATPase provides the driving force for passive ion transport systems.

A previous study showed the mats of ciliated cells in rat tracheal epithelium post-thermal injury (Dubick et al. 2002). Thermal stress regulates ENaCs in alveolar epithelial cells (Howard et al. 2013) and CFTR is implicated in thermal stress-induced signaling events in bronchial epithelial cells (Dong et al. 2015). Additionally, $\mathrm{Na}^{+} / \mathrm{K}^{+}$-ATPase is heat-sensitive in rabbit esophageal epithelium (Tobey et al. 1999). However, whether thermal stress regulates permeability of the airway epithelial barrier through the paracellular pathway (mediated by tight junctions) and the transcellular pathway (mediated by ion channels and transporters) in primary airway epithelial cells remains unclear.

Smoke aldehydes are released from the burning of wood and paper products, as well as cotton fabrics. Formaldehyde and acrolein 
3 are the two main gaseous $\alpha, \beta$ unsaturated aldehydes in fire and cigarette smoke (Reinhardt and Ottmar 2004; Anthony et al. 2007; Alwis

4 et al. 2015). Inhalation of formaldehyde and acrolein results in gene induction, inflammation, cell apoptosis, and necrosis in the

5 respiratory epithelium (Bein and Leikauf 2011; Meacher and Menzel 1999). Our previous studies showed that formaldehyde and

6 crotonaldehyde inhibited the activity and expression of ENaCs in alveolar epithelial cells (Cui et al. 2016; Li et al. 2017). Acrolein led

7 to irritation of the airway and impaired fluid homeostasis (Borchers et al. 1998; Romet-Haddad et al. 1992; Roux et al. 2002), as well

8 as downregulated CFTR activity in respiratory epithelial cells (Alexander et al. 2012). Acrolein is used to prepare animal models for

9 acute lung injury and lung edema (Hales et al. 1988). However, the pathological role of acrolein in the presence of thermal stress in the

0 smoke-injured airway epithelial barrier has not been studied.

1 Therefore, this study aimed to investigate the effects of thermal stress or/and acrolein on permeability of the airway epithelial barrier.

2 We recorded the transepithelial resistance $\left(\mathrm{R}_{\mathrm{TE}}\right)$ and short-circuit current $\left(\mathrm{I}_{\mathrm{SC}}\right)$ in primary mouse tracheal epithelial (MTE) monolayers

3 in an Ussing chamber setup. To further determine the underlying transcellular mechanisms, inhibitors for ion channels and transporters

4 (i.e., amiloride, ouabain, and CFTRinh-172) were applied to MTE monolayers. To examine the role of the paracellular pathway, the tight

5 junctions were visualized under confocal microscopy, and the fluorescein isothiocyanate (FITC)-dextran assay was performed.

\section{Materials and methods}

8 Animals

9 Forty healthy wild-type C57BL/6 mice (males, 20; females, 20), 8-12 weeks old (mean: $10.86 \pm 0.28$ weeks) and weighed 18-25 g

0 (mean: $20.03 \pm 0.30 \mathrm{~g}$ ), were purchased from the Jackson Laboratory and the Laboratory Animal Center of China Medical University.

1 Mice were housed in a pathogen-free facility, the husbandry condition of which included a suitable light/dark cycle, temperature,

2 drinking water, and food. All experiments were performed according to the guidelines and regulations of the Animal Care and Use Ethics

3 Committee, and all protocols were approved by the University of Texas Health Science Center at Tyler and China Medical University.

4 The reference numbers of ethics approval are IACUC 611 and SCXK (Liao) 2018-0001. 
5 Isolation and culture of MTE cells

6 Pooled MTE cells were isolated from C57BL/6 mice and cultured according to our previous study (Chen et al. 2014). Briefly, tracheas

7 of anesthetized mice were removed, and cleaned tracheas were incubated in Dulbecco's modified eagle medium (cat\# 30-2002, American

8 Type Culture Collection, USA) containing 0.1\% protease XIV (cat\# P5147, Sigma, USA), 0.01\% DNase (cat \#DN25, Sigma-Aldrich,

9 St. Louis, MO), and 1\% fetal bovine serum (cat\# 26140-087, Gibco, USA) at $4^{\circ} \mathrm{C}$ for $24 \mathrm{~h}$. MTE cells were seeded onto 6.5 -mm diameter,

0 collagen IV (cat\# 3410-010-01, Trevigen, Gaithersburg, MD)-coated transwell inserts (cat\# 3413, Corning-Costar, Lowell, MA) at a

1 density of $3.0 \times 10^{5} / \mathrm{cm}^{2}$. These cells were grown in a 1:1 mixture of Ham's F-12 medium (cat\# 11765-054, Invitrogen, Camarillo, CA)

2 and 3T3 fibroblast preconditioned Dulbecco's modified eagle medium supplemented with insulin (10 $\mu \mathrm{g} / \mathrm{ml}, \mathrm{cat} \# \mathrm{I} 1882$, Sigma-Aldrich,

3 St. Louis, MO), hydrocortisone (1 $\mu \mathrm{M}$, cat\# H0396, Sigma-Aldrich, St. Louis, MO), endothelial cell growth supplement (3.75 $\mu$ g/ml,

4 cat\# E0760, Sigma-Aldrich, St. Louis, MO), epidermal growth factor (25 ng/ml, cat\# E4127, Sigma-Aldrich, St. Louis, MO),

5 triiodothyronine (30 nM, cat\# T6397, Sigma-Aldrich, St. Louis, MO), iron-saturated transferrin (5 $\mu \mathrm{g} / \mathrm{ml}, \mathrm{cat} \# \mathrm{~T} 1283$, Sigma-Aldrich,

6 St. Louis, MO), cholera toxin (10 ng/ml, cat\# C8052, Sigma-Aldrich, St. Louis, MO), and dexamethasone (250 nM, cat\# D2915, Sigma-

7 Aldrich, St. Louis, MO). MTE cells from one mouse were seeded onto three to four transwell inserts and cultured for up to 12 days.

8 Polarized monolayers with a reading of $\mathrm{R}_{\mathrm{TE}}>1000 \Omega$ by an epithelial voltohmmeter (WPI, Sarasota, FL) were used. Monolayers from

9 the same batch of mice were randomly allocated to control and treated groups.

0 Preparation of human bronchial epithelial monolayers

1 Human bronchial epithelial (HBE) cells were purchased from American Type Culture Collection. Cells were seeded in plastic T-75

2 flasks and grown in keratinocyte culture medium (cat\# 2101, Sciencell, China) supplemented with keratinocyte growth factor (1\%). The

3 culture medium was changed every $48 \mathrm{~h}$ until $90 \%$ confluent. HBE cells were seeded $\left(10^{6}\right.$ cells $\left./ \mathrm{cm}^{2}\right)$ onto collagen IV-coated transwell

4 inserts and grown in keratinocyte culture medium supplemented with keratinocyte growth factor (1\%), insulin-transferrin-selenium

5 solution, (1.5\%, cat\# 41400045, Gibco, USA) and dexamethasone (1 $\mu$ M, cat\# D2915, Sigma-Aldrich, St. Louis, MO). Polarized

6 monolayers at 12-day post-seeding were used. At all stages of culture, cells were maintained at $37^{\circ} \mathrm{C}$ in $5 \% \mathrm{CO}_{2}$ in an air incubator. 
1 Preparation and administration of ion transport regulators

8 Amiloride (an inhibitor for ENaCs, cat\# A4562, Sigma-Aldrich, St. Louis, MO) was reconstituted in an apical bath solution containing

$950 \%$ dimethyl sulfoxide (DMSO). CFTRinh-172 (an inhibitor for CFTR, cat\# C2992, Sigma-Aldrich, St. Louis, MO) was reconstituted

0 in DMSO. Ouabain (an inhibitor for $\mathrm{Na}^{+} / \mathrm{K}^{+}$-ATPase, cat\# O3125, Sigma-Aldrich, St. Louis, MO) was reconstituted in a basolateral bath

1 solution. Reconstituted amiloride $(100 \mu \mathrm{M})$ or CFTRinh-172 $(20 \mu \mathrm{M})$ was added to the apical bath solution of MTE monolayers.

2 Reconstituted ouabain $(1 \mathrm{mM})$ was added to the basolateral bath solution. Vehicle solution of an equal volume was added to the

3 corresponding bath solution as the control.

4 Concurrent measurements of IsC and RTE

5 Measurement of ISC and RTE of MTE or HBE monolayers was performed as we described previously (Han et al. 2010; Nie et al. 2009;

6 Li et al. 2017). In brief, monolayers were mounted into Ussing chambers (Physiologic Instruments, San Diego, CA) and bathed in saline

7 solution containing (in $\mathrm{mM}$ ) $120 \mathrm{NaCl}, 25 \mathrm{NaHCO}_{3}, 3.3 \mathrm{KH}_{2} \mathrm{PO}_{4}, 0.83 \mathrm{~K}_{2} \mathrm{HPO}_{4}, 1.2 \mathrm{CaCl}_{2}, 1.2 \mathrm{MgCl}_{2}, 10 \mathrm{HEPES}, 10 \mathrm{D}$-mannitol

8 (apical), and $10 \mathrm{D}$-glucose (basolateral). The saline bath solution was bubbled continuously with a gas mixture of $95 \% \mathrm{O}_{2}$ and $5 \% \mathrm{CO}_{2}$.

9 Transepithelial potential was short-circuited to $0 \mathrm{mV}$, and $\mathrm{R}_{\mathrm{TE}}$ and Isc levels were measured with an epithelial voltage clamp (VCC-

0 MC8, Physiologic Instruments, San Diego, CA). A 10-mV pulse of $1 \mathrm{~s}$ duration was imposed every $10 \mathrm{~s}$ to monitor RTE levels. When

$1 \mathrm{R}_{\mathrm{TE}}$ and ISC levels were stable for at least $10 \mathrm{~min}$, monolayers were treated as follows: 1$)$ amiloride $(100 \mu \mathrm{M})$ was added to the apical

2 bath solution; 2) CFTRinh-172 $(20 \mu \mathrm{M})$ was added to the apical bath solution; 3$)$ ouabain $(1 \mathrm{mM})$ was applied to the basolateral bath

3 solution; and 4) saline bath solution of both apical and basolateral chambers was replaced with $\mathrm{Na}^{+}$-free bath solution or $\mathrm{Cl}^{-}$-free bath

4 solution. The same volume of vehicle solution was added to corresponding chambers, which was used as the control of amiloride,

5 CFTRinh-172, or ouabain. The composition of the $\mathrm{Na}^{+}$-free bath solution contained (in mM) $120 \mathrm{~N}$-methyl-D-glucamine- $\mathrm{Cl}_{2}, 25 \mathrm{KHCO}_{3}$,

$6 \quad 3.3 \mathrm{KH}_{2} \mathrm{PO}_{4}, 0.83 \mathrm{~K}_{2} \mathrm{HPO}_{4}, 1.2 \mathrm{CaCl}_{2}, 1.2 \mathrm{MgCl}_{2}, 10 \mathrm{HEPES}, 10 \mathrm{D}$-mannitol (apical), and 10 D-glucose (basolateral). The $\mathrm{Cl}^{-}$-free bath

7 solution contained (in mM) 120 sodium gluconate, $25 \mathrm{NaHCO}_{3}, 3.3 \mathrm{KH}_{2} \mathrm{PO}_{4}, 0.83 \mathrm{~K}_{2} \mathrm{HPO}_{4}, 1.2 \mathrm{Ca}\left(\mathrm{NO}_{3}\right)_{2}, 1.2 \mathrm{MgSO}$, $10 \mathrm{HEPES}, 10$

8 D-mannitol (apical), and $10 \mathrm{D}$-glucose (basolateral). Before replacement of $\mathrm{Na}^{+}$-free or $\mathrm{Cl}^{-}$-free bath solution, recording of $\mathrm{R}_{\mathrm{TE}}$ and ISC 
9 in the Ussing chamber system was stopped, and then saline bath solution was aspirated from the apical and basolateral chambers. Warm

0 saline (as the control), $\mathrm{Na}^{+}$-free bath solution, or $\mathrm{Cl}^{-}$-free bath solution was then added to the chambers. Finally, recording in the Ussing

1 chamber system was restored.

2 Application of thermal stress or acrolein to monolayers

3 All experiments of thermal stress or acrolein application were simultaneously performed with recording in the Ussing chamber system.

4 In the experiments for studying the effects of thermal stress on $\mathrm{R}_{\mathrm{TE}}$ and ISC, and the underlying mechanisms, monolayers were mounted

5 into the chambers in which the temperature was $37^{\circ} \mathrm{C}$. The temperature of bath solution of the apical and basolateral chambers was

6 gradually elevated to the designed degree $\left(40^{\circ} \mathrm{C}\right)$ from $37^{\circ} \mathrm{C}$. A bath circulator (Thermo Fisher Scientific, CA) was used to regulate the

7 temperature of the chambers. The bath circulator was set to the desired temperature. Water was pumped from the bath of the circulator

8 and continuously recirculated around the chambers, thereby transferring heat to the bath solution in the chambers. Additionally,

9 thermometers in the apical and basolateral bath solution of the chambers were used to monitor and confirm the temperature setting. In

0 the experiments for investigating the effects of thermal stress on ion transport system, the bath solution in the chambers was first set to

1 the desired temperature $\left(40^{\circ} \mathrm{C}\right)$, and then monolayers were mounted into chambers to achieve instant exposure of thermal stress. In the

2 experiments of acrolein exposure, a range of working concentrations from 5 to $500 \mu \mathrm{M}$ was accumulatively pipetted into the apical bath

3 solution. Acrolein vapor was minimized without gas bubbling of the bath solution, and the bath solution was moderately blown up to 10

4 times to ensure even distribution of acrolein. To study the synergistic effects of acrolein and thermal stress, monolayers were mounted

5 into chambers in which the temperature was already $40^{\circ} \mathrm{C}$ or $37^{\circ} \mathrm{C}$ (as the control). When RTE and Isc traces were stable, a series of

6 concentrations of acrolein were added to the apical bath solution.

7 Immunofluorescent staining and imaging of MTE monolayers

8 MTE monolayers that were bathed in saline solution in Ussing chambers were exposed to $40^{\circ} \mathrm{C}(120 \mathrm{~min})$ or acrolein $(500 \mu \mathrm{M})$. For

9 synergistic treatment of thermal stress and acrolein, MTE monolayers were bathed in saline solution $\left(40^{\circ} \mathrm{C}\right.$ or $\left.37^{\circ} \mathrm{C}\right)$, and then $500 \mu \mathrm{M}$

0 acrolein was added to the apical bath solution. After this treatment, monolayers were prepared for staining. Monolayers were fixed in 
1 phosphate-buffered saline containing 4\% paraformaldehyde for $15 \mathrm{~min}$ and washed with phosphate-buffered saline. Monolayers were

2 permeabilized with $0.5 \%$ Triton X-100 and blocked with a blocking buffer containing 10\% goat serum (cat\# G9023, Sigma-Aldrich, St.

3 Louis, MO) and 1\% bovine serum albumin (cat\# A3803, Sigma-Aldrich, St. Louis, MO) for $1 \mathrm{~h}$. Monolayers were incubated with rabbit

4 anti-mouse zonula occludens-1 (ZO-1) antibody (1:50; cat\# 61-7300, Invitrogen, Camarillo, CA) or rabbit anti-mouse occludin antibody

5 (1:200; cat\# 40-4700, Invitrogen, Camarillo, CA) in blocking buffer overnight at $4^{\circ} \mathrm{C}$. Cells were incubated with Alexa Fluor 488 -

6 labeled goat anti-rabbit IgG (1:1000, cat\# 111-545-045 Jackson Immuno Research Laboratories, Carlsbad, CA) and Hoechst (1:1000,

7 cat\# 561908, BD Biosciences, San Jose, CA) and then mounted with Vectashield mounting media (cat\# H1000, Vector Laboratories,

8 Burlingame, CA). Images were obtained with a Zeiss LSM 510 confocal microscope (Carl Zeiss AG, Germany). A series of optical

9 sections were collected at $1-\mu \mathrm{m}$ intervals in the Z-axis. Images and quantification of fluorescence intensity were analyzed with ImageJ

$0 \quad(\mathrm{NIH})$

1 Cell counting kit-8 assay

2 Cell viability was quantified by the cell counting kit-8 assay (cat\# C0037, Beyotime, Jiangsu, China). Culture medium containing $10 \%$

3 cell counting kit-8 solution was added apically to MTE monolayers at post-treatment of $37^{\circ} \mathrm{C}$ (control), $40^{\circ} \mathrm{C}(120 \mathrm{~min})$, acrolein $(500$

$4 \mu \mathrm{M}$ ), or $40^{\circ} \mathrm{C}$ combined with acrolein. After $2 \mathrm{~h}$ of incubation at $37^{\circ} \mathrm{C}$, culture medium in transwell inserts was collected. Absorbance

5 was measured at a wavelength of $450 \mathrm{~nm}$.

6 FITC-dextran assay

7 To measure dextran permeability, FITC-dextran (4 kDa, $1 \mathrm{mg} / \mathrm{ml}$, cat\# FD4, Sigma-Aldrich, St. Louis, MO) was added to the transwell

8 inserts. Aliquots were withdrawn from the lower chambers after $4 \mathrm{~h}$ and assayed for fluorescence at $530 \mathrm{~nm}$.

$9 \quad$ Statistical analysis

$0 \quad$ Data are expressed as the mean \pm SEM. Normality and homoscedasticity tests were performed by the Shapiro-Wilk and Levene tests.

1 The real power of the sample size with alpha $=0.05$ is shown in the figure legends. The student's two-tailed t-test was used for comparing

2 two groups with parametric data. For comparison of multiple groups, we performed one-way analysis of variance followed by 
3 Bonferroni's test for all groups in the experiments. For non-parametric data, the Mann-Whitney U test was used. Differences were

4 considered significant when the $P$ value was $<0.05$. The $\tau_{1 / 2}$ value was computed by fitting $\mathrm{R}_{\mathrm{TE}}$ raw data with the ExpDec 1 function

$5\left(y=y_{0}+A e^{-x / t}\right)$, where $y$ is RTE, $x$ is time, $y_{0}$ is offset; and $A$ is amplitude. The dose-response curve for acrolein was generated

6 by fitting the raw data with the Hill equation $\left(y=\operatorname{START}+(E N D-S T A R T) \frac{x^{n}}{k^{n}+x^{n}}\right)$, where $y$ is the normalized $\mathrm{R}_{\mathrm{TE}} / \mathrm{ISC}_{\mathrm{SC}}$ value, $x$ is

7 the logarithmic concentration of acrolein, START and END are initial and ending values of RTE, respectively, $k$ is the $K_{\mathrm{i}}$ value, and $n$ is

8 the total number of $x$. In thermal stress-treated $\mathrm{R}_{\mathrm{TE}} / \mathrm{ISC}_{\mathrm{SC}}$ traces, $\Delta \mathrm{R}_{\mathrm{TE}}$ was defined as the difference between the initial $\mathrm{R}_{\mathrm{TE}}$ and end of

$9 \mathrm{R}_{\mathrm{TE}}$ within one phase (phase $1[\mathrm{P} 1]$ or phase $2[\mathrm{P} 2]$ ) or the entire procedure, and $\triangle \mathrm{I}_{\mathrm{SC}}$ was defined as the difference between the basal

0 Isc and the peak Isc at P1 or the difference between the peak Isc and end of Isc at P2. In acrolein-treated RTE/ISC traces, $\triangle R_{\mathrm{TE}} / \Delta \mathrm{ISC}_{\mathrm{SC}}$ was

1 defined as the difference between basal $\mathrm{R}_{\mathrm{TE}} / \mathrm{ISC}_{\mathrm{SC}}$ and acrolein-resistant $\mathrm{R}_{\mathrm{TE}} / \mathrm{ISC}_{\mathrm{SC}}$. ENaCs, CFTR, or $\mathrm{Na}^{+} / \mathrm{K}^{+}$-ATPase activity was determined

2 as the difference between the basal IsC and corresponding specific inhibitor-resistant Isc. Statistical analysis was performed with Origin

3 Pro 8.0 (OriginLab Corp. MA).

4

5 Results

6 Thermal stress alters RTE and Isc in MTE and HBE monolayers

7 The airway epithelial barrier is the primary line of defense against external attacks. Under pathogenic conditions, the integrity of this

8 barrier is damaged and permeability is increased. We postulated that thermal stress would regulate permeability of the airway epithelium.

9 In our study, basal RTE and Isc in polarized MTE monolayers were recorded at $37^{\circ} \mathrm{C}$. To investigate the effect of thermal stress, the

0 temperature of the bath solution was elevated from $37^{\circ} \mathrm{C}$. $\mathrm{R}_{\mathrm{TE}}$ and ISC were eliminated in minutes when the temperature of the bath

1 solution was elevated to $44^{\circ} \mathrm{C}$ or $42^{\circ} \mathrm{C}$ (Fig. S1). Therefore, $40^{\circ} \mathrm{C}$ was selected for the temperature of thermal stress. RTE was decreased

2 when the temperature of the bath solution was raised to $40^{\circ} \mathrm{C}$ from $37^{\circ} \mathrm{C}$. Moreover, the entire process was divided into two stages of

3 P1 and P2 (Fig. 1a). At each phase, RTE was significantly decreased in a time-dependent manner (Fig. 1c). We used $\tau_{1 / 2}$ to reflect the

4 declining rate of $\mathrm{R}_{\mathrm{TE}}$ within one phase, which was computed by fitting $\mathrm{R}_{\mathrm{TE}}$ raw data with the ExpDec1 function. The $\tau_{1 / 2}$ at $\mathrm{P} 2$ was 
5 significantly higher than that at P1 (Fig. 1e, $P<0.001$ ). We defined P1 and P2 of IsC using the RTE time course. In contrast, ISC, which

6 was recorded in parallel with $\mathrm{R}_{\mathrm{TE}}$, was increased at P1 and decreased at P2 (Fig. 1b and 1d, all $P<0.01$ ). To overcome the difference

7 between species, we recorded $\mathrm{R}_{\mathrm{TE}}$ and $\mathrm{ISC}_{\mathrm{SC}}$ in $\mathrm{HBE}$ monolayers during thermal stress. We found that $\mathrm{R}_{\mathrm{TE}}$ of $\mathrm{HBE}$ monolayers was

8 decreased by thermal stress, which was similar to the result from MTE monolayers (Fig. 1f and 1h, $P=0.077$ ). However, IsC of HBE

9 monolayers was increased to a high and stable level by thermal stress (Fig. $1 \mathrm{~g}$ and $\left.1 \mathrm{i},{ }^{*} P<0.05\right)$. Our data suggest that RTE and Isc of

0 primary MTE monolayers respond to thermal stress in a phase-dependent, diverse manner.

$1 \quad \mathrm{Na}^{+}$transport mediates thermal stress-induced bioelectric changes

2 In respiratory epithelium, $\mathrm{Na}^{+}$transport is mainly regulated by ENaCs and $\mathrm{Na}^{+} / \mathrm{K}^{+}$-ATPase (Chang et al. 2018). Passive ion transport

3 across tight epithelial monolayers includes ion channels (i.e., ENaCs) and transporters, which are an important determinant of

4 transcellular permeability. Active $\mathrm{Na}^{+} / \mathrm{K}^{+}$-ATPase provides the driving force for the passive ion transport systems. To examine the role

5 of epithelial $\mathrm{Na}^{+}$transport in thermal stress-altered $\mathrm{RTE}$ and Isc, $\mathrm{Na}^{+}$-free bath solution, amiloride, or ouabain was applied to MTE

6 monolayers bathed in Ussing chambers at $37^{\circ} \mathrm{C}$ followed by elevation to $40^{\circ} \mathrm{C}$. At $37^{\circ} \mathrm{C}$, $\mathrm{Na}^{+}$-free bath solution and amiloride, but not

1 ouabain, caused an increment in $\mathrm{R}_{\mathrm{TE}}$ (Fig. 2a, black line). A drop in ISC was seen at this time (Fig. 2b, black line). During thermal stress,

$8 \mathrm{R}_{\mathrm{TE}}$ was decreased in a two-phase manner in the presence of amiloride, which was similar to the result from the saline group. In contrast,

9 a continuous decrease in $\mathrm{R}_{\mathrm{TE}}$ was observed in the presence of $\mathrm{Na}^{+}$-free bath solution or ouabain, which could not be divided into two

0 significant phases (Fig. 2a, red line). IsC at P1 and P2 was observed in the presence of $\mathrm{Na}^{+}$-free bath solution or amiloride (Fig. 2b, red

1 line). We computed thermal stress-sensitive $\mathrm{R}_{\mathrm{TE}}$ at $\mathrm{P} 1$ and $\mathrm{P} 2\left(\triangle \mathrm{R}_{\mathrm{TE}}\right.$, in Fig. $\left.2 \mathrm{c}\right)$, and found that amiloride markedly increased thermal

2 stress-sensitive $\mathrm{R}_{\mathrm{TE}}$ at $\mathrm{P} 1(P<0.01)$, but there were no significant effects at $\mathrm{P} 2(P=0.56)$. Thermal stress caused the continuous reduction

3 of $\mathrm{R}_{\mathrm{TE}}$ in the presence of the $\mathrm{Na}^{+}$-free bath solution and ouabain, so we calculated thermal stress-sensitive $\mathrm{R}_{\mathrm{TE}}$ in the entire procedure

$4 \quad\left(\triangle \mathrm{R}_{\mathrm{TE}}\right.$ in Fig. $\left.2 \mathrm{~d}\right)$, and found that $\mathrm{Na}^{+}$-free bath solution markedly increased thermal stress-sensitive $\mathrm{R}_{\mathrm{TE}}$ and ouabain significantly

5 decreased thermal stress-sensitive $\mathrm{R}_{\mathrm{TE}}$ in the entire of procedure (all $P<0.05$ ). We calculated thermal stress-sensitive IsC at $\mathrm{P} 1$ and $\mathrm{P} 2$

$6\left(\triangle \mathrm{ISC}_{\mathrm{SC}}\right.$, in Fig. 2e and 2f), and found that thermal stress-sensitive Isc at P1 was significantly decreased in the presence of Na ${ }^{+}$-free bath 
7 solution, amiloride, or ouabain (Fig. 2e, all $P<0.05$ ). Additionally, $\mathrm{Na}^{+}$-free bath solution and amiloride markedly decreased thermal

8 stress-sensitive Isc at P2 (Fig. 2f, $P<0.001$ ). Because we could not observe the obvious Isc P2 in the presence of ouabain, we did not

9 calculate thermal stress-sensitive ISC at P2 in the presence of ouabain. These data indicate that changes in $\mathrm{R}_{\mathrm{TE}}$ and ISC caused by thermal

0 stress may be predominately determined by transcellular $\mathrm{Na}^{+}$transport powered by ENaCs and $\mathrm{Na}^{+} / \mathrm{K}^{+}-\mathrm{ATPase}$. Interestingly, blockade

1 of $\mathrm{Na}^{+} / \mathrm{K}^{+}$-ATPase showed lower thermal stress-sensitive Isc compared with $\mathrm{Na}^{+}$-free bath solution. The potential mechanisms of this

2 finding may be the temperature-dependent $\mathrm{Na}^{+} / \mathrm{K}^{+}$-ATPase and others, including ENaCs, CFTR, and $\mathrm{K}^{+}$channels (KCs). We attempted

3 to further confirm the effects of thermal stress on permeabilized half monolayers. However, neither RTE nor Isc levels were stable enough

4 to perform further analysis (Fig. S2).

5 CFTR is required for thermal stress-induced alteration

6 We next examined the contribution of epithelial $\mathrm{Cl}^{-}$transport to thermal stress-induced alterations in $\mathrm{R}_{\mathrm{TE}}$ and ISC of MTE monolayers.

7 Transcellular $\mathrm{Cl}^{-}$transport via apical CFTR comprises majority of transcellular anion flux (Sheppard and Welsh 1999; Fuller and Benos

8 1992). At $37^{\circ} \mathrm{C}, \mathrm{Cl}^{-}$-free bath solution or CFTRinh-172 was applied to block overall epithelial $\mathrm{Cl}^{-}$transport or CFTR. Blockade of CFTR

9 led to an increment in $\mathrm{R}_{\mathrm{TE}}$ and a drop in IsC (Fig. 3a and 3b, black line). However, $\mathrm{Cl}^{-}$-free bath solution caused a transient increment,

0 followed by a slow decline to $0.24 \pm 0.03 \mathrm{k} \Omega \times \mathrm{cm}^{2}$ in RTE and almost zero in Isc (Fig. S3). Therefore, we could not perform further

1 analysis. During thermal stress, RTE and ISC were changed in a two-phase manner in the presence of CFTRinh-172, which was similar

2 to the saline group (Fig. 3a and 3b, red line). CFTRinh-172 significantly increased thermal stress-sensitive R

3 all $P<0.01$ ). CFTRinh-172 significantly decreased thermal stress-sensitive Isc for both phases (Fig. $3 \mathrm{~d}$ and $3 \mathrm{e}, P<0.05$ ). These

4 findings suggest that CFTR plays a role in changes in RTE and ISC caused by thermal stress.

5 Steady-state elevated temperature increases transcellular ion channel activity

6 To confirm the two-phase alteration in Isc following a gradual rise in bath temperature, we alternatively mounted MTE monolayers to

7 Ussing chambers that were already set at $40^{\circ} \mathrm{C}$. Interestingly, elevated and stable total Isc levels were observed under this steady-state,

8 elevated temperature condition, which was different from the two-phase manner when the temperature was gradually elevated (Fig. 4a, 
$94 \mathrm{c}$, and 4e, basal Isc of the black line and red line). These observations suggested that the time course of thermal stress determined the

0 severity of impaired transcellular ion transport in MTE monolayers. To inhibit the activity of ion channels and transporters, including

1 ENaCs, CFTR, and $\mathrm{Na}^{+} / \mathrm{K}^{+}$-ATPase, their specific inhibitors, including amiloride, CFTRinh-172, and ouabain, were added to a bath

2 solution at $37^{\circ} \mathrm{C}$ or $40^{\circ} \mathrm{C}$. IsC was inhibited by these specific inhibitors at $37^{\circ} \mathrm{C}$ and $40^{\circ} \mathrm{C}$ (Fig. $4 \mathrm{a}$, $4 \mathrm{c}$, and $4 \mathrm{e}$ ). We computed total IsC,

3 specific inhibitor-resistant Isc, and the difference between these two Isc (Figs. 4b, 4d, and 4f). The difference between total Isc and

4 specific inhibitor-resistant ISC reflected the activity of corresponding ion channels or transporters, and we found that thermal stress

5 increased the activity of ENaCs, CFTR and $\mathrm{Na}^{+} / \mathrm{K}^{+}$-ATPase (all $P<0.05$ ). We also computed the basal $\mathrm{R}_{\mathrm{TE}}$ value and post-inhibitor

6 value applying at $37^{\circ} \mathrm{C}$ or $40^{\circ} \mathrm{C}$ (Fig. $\left.4 \mathrm{~g}\right)$. The mean basal $\mathrm{R}_{\mathrm{TE}}$ level at $40^{\circ} \mathrm{C}\left(0.57 \pm 0.05 \mathrm{k} \Omega \times \mathrm{cm}^{2}\right)$ was significantly less than that at

$7 \quad 37^{\circ} \mathrm{C}\left(1.08 \pm 0.06 \mathrm{k} \Omega \times \mathrm{cm}^{2}\right)(P<0.001)$. An increase in $\mathrm{R}_{\mathrm{TE}}$ was observed in the presence of amiloride and CFTRinh-172 (all $\left.P<0.05\right)$

8 but not ouabain (all $P>0.05$ ), at $37^{\circ} \mathrm{C}$ and $40^{\circ} \mathrm{C}$. These data suggest that a steady-state elevated temperature increases the activity of

9 ENaCs, CFTR, and $\mathrm{Na}^{+} / \mathrm{K}^{+}$-ATPase.

$0 \quad$ Acrolein downregulates $\mathrm{R}_{\mathrm{TE}}$ and $\mathrm{I}_{\mathrm{SC}}$

1 Our previous studies showed that formaldehyde and crotonaldehyde regulated ENaCs in alveolar epithelial cells (Cui et al. 2016; Li et

2 al. 2017). Acrolein is an industrial chemical of high toxicity and a toxic combustion product (Stevens and Maier 2008), and

3 concentrations of which can vary widely in different fire and tobacco smoke. One kilogram of different types of wood can produce

$4 \quad 0.374-2.35 \mathrm{mM}$ of acrolein (Faroon et al. 2008). In the case of burning of tobacco, the acrolein concentrations are $34-503 \mu \mathrm{M}$ when

5 smoke from a single cigarette is bubbled through $10 \mathrm{ml}$ of buffered saline (Burcham et al. 2010). To examine the effects of acrolein on

6 the permeability of MTE monolayers, acrolein (approximately $500 \mu \mathrm{M}$ ) was applied to monolayers bathed at $37^{\circ} \mathrm{C}$ and at a steady-state

7 of $40^{\circ} \mathrm{C}$. A total of $500 \mu \mathrm{M}$ acrolein decreased $\mathrm{R}_{\mathrm{TE}}$ and $\mathrm{ISC}_{\mathrm{SC}}$ at $37^{\circ} \mathrm{C}$ and $40^{\circ} \mathrm{C}$ (Fig. $5 \mathrm{a}$ and $5 \mathrm{~b}$ ). To compare the difference in effects of

8 acrolein at $37^{\circ} \mathrm{C}$ and $40^{\circ} \mathrm{C}$, the dose-response curve for acrolein was generated by fitting raw data points with the Hill equation. By

9 fitting raw $\mathrm{R}_{\mathrm{TE}}$ data, we found that the $K_{\mathrm{i}}$ value for acrolein was $120.22 \mu \mathrm{M}$ at $37^{\circ} \mathrm{C}$ and $79.43 \mu \mathrm{M}$ at $40^{\circ} \mathrm{C}(\mathrm{Fig}$. $5 \mathrm{c}$ ). By fitting raw ISC

0 data, we found that the $K_{\mathrm{i}}$ value for acrolein was $125.89 \mu \mathrm{M}$ at $37^{\circ} \mathrm{C}$ and $77.62 \mu \mathrm{M}$ at $40^{\circ} \mathrm{C}$ (Fig. $5 \mathrm{~d}$ ). In $\mathrm{HBE}$ monolayers, a reduction 
1 of $\mathrm{R}_{\mathrm{TE}}$ and ISC caused by $500 \mu \mathrm{M}$ acrolein was observed, which was similar to the result from MTE monolayers (Fig. 5e and 5f). In the

$2 \mathrm{R}_{\mathrm{TE}}$ dose-response curve of $\mathrm{HBE}$ monolayers, the $K_{\mathrm{i}}$ value for acrolein was $83.18 \mu \mathrm{M}$ at $37^{\circ} \mathrm{C}$ and $97.73 \mu \mathrm{M}$ at $40^{\circ} \mathrm{C}$ (Fig. $5 \mathrm{~g}$ ). In the

3 Isc dose-response curve of $\mathrm{HBE}$ monolayers, the $K_{\mathrm{i}}$ value for acrolein was $125.89 \mu \mathrm{M}$ at $37^{\circ} \mathrm{C}$ and $112.21 \mu \mathrm{M}$ at $40^{\circ} \mathrm{C}$ (Fig. $5 \mathrm{~h}$ ). Our

4 data suggest that acrolein impairs airway epithelial permeability in an atypical concentration-dependent manner and an elevated

5 temperature exacerbates this damaging process.

$6 \mathrm{Na}^{+}$transport participates in acrolein-induced reduction of $\mathrm{R}_{\mathrm{TE}}$ and $\mathrm{I}_{\mathrm{SC}}$

7 We examined the role of epithelial $\mathrm{Na}^{+}$transport on the decrease in $\mathrm{R}_{\mathrm{TE}}$ and ISC by acrolein in MTE monolayers. At the basal level of $837^{\circ} \mathrm{C}, \mathrm{Na}^{+}$-free bath solution, amiloride, or ouabain was used to block overall epithelial $\mathrm{Na}^{+}$transport, $\mathrm{ENaCs}$ or $\mathrm{Na}^{+} / \mathrm{K}^{+}$-ATPase. After 9 pre-inhibition of these $\mathrm{Na}^{+}$transport pathways, $500 \mu \mathrm{M}$ acrolein was added to the apical bath solution, and changes in $\mathrm{R}_{\mathrm{TE}}$ and $\mathrm{I}_{\mathrm{SC}}$ caused 0 by acrolein were observed. At $37^{\circ} \mathrm{C}, \mathrm{Na}^{+}$-free bath solution and amiloride, but not ouabain, caused an increment in $\mathrm{R}_{\mathrm{TE}}$ (Fig. $6 \mathrm{a}$, black 1 line). Additionally, a drop in Isc induced by $\mathrm{Na}^{+}$-free bath solution, amiloride, and ouabain, was observed (Fig. 6b, black line). During 2 exposure of $500 \mu \mathrm{M}$ acrolein, $\mathrm{R}_{\mathrm{TE}}$ was decreased in the presence of $\mathrm{Na}^{+}$-free bath solution, amiloride, and ouabain (Fig. 6a, blue line).

3 Acrolein continuously decreased IsC in the presence of amiloride but showed no obvious effect in the presence of $\mathrm{Na}^{+}$-free bath solution 4 and ouabain (Fig. 6b, blue line). We calculated acrolein-sensitive $R_{\mathrm{TE}}\left(\triangle \mathrm{R}_{\mathrm{TE}}\right.$, Fig. $\left.6 \mathrm{c}\right)$, and found that $\mathrm{Na}^{+}$-free bath solution, amiloride, 5 and ouabain significantly increased acrolein-sensitive $\mathrm{R}_{\mathrm{TE}}(P<0.05)$. Acrolein-sensitive $\mathrm{I}_{\mathrm{SC}}\left(\triangle \mathrm{I}_{\mathrm{SC}}, \mathrm{Fig}\right.$. 6d) was also computed, and it 6 was significantly decreased by $\mathrm{Na}^{+}$-free bath solution, amiloride, and ouabain (all $P<0.01$ ). These data suggest that changes in $\mathrm{R}_{\mathrm{TE}}$ and 7 Isc induced by acrolein may be related to transcellular pathways that are mediated by $\mathrm{ENaCs}$ and $\mathrm{Na}^{+} / \mathrm{K}^{+}-\mathrm{ATPase}$.

8 CFTR mediates the acrolein-induced reduction in $\mathrm{R}_{\mathrm{TE}}$ and ISC

9 We further examined the role of CFTR in the decrease in $\mathrm{R}_{\mathrm{TE}}$ and ISC by acrolein in MTE monolayers. At basal level of $37^{\circ} \mathrm{C}$, CFTRinh0172 was used to inhibit CFTR, and then $500 \mu \mathrm{M}$ acrolein was added to the monolayers. Changes in RTE and IsC caused by acrolein were 1 observed. At the basal level, CFTRinh-172 increased RTE (Fig. 7a, black line) and decreased IsC (Fig. 7b, black line). During exposure 2 of acrolein, $\mathrm{R}_{\mathrm{TE}}$ and IsC were decreased (Figs. 7a and 7b, blue line). CFTRinh-172 significantly increased acrolein-sensitive R $\mathrm{R}_{\mathrm{TE}}$ (Fig. 
$37 \mathrm{c}, P<0.01$ ) and markedly decreased acrolein-sensitive Isc (Fig. $7 \mathrm{~d}, P<0.001$ ). These findings suggest that CFTR may participate in

4 the reduction of RTE and Isc caused by acrolein.

5 Thermal stress and acrolein impair tight junctions

6 Our findings suggested that the transcellular pathway is required for the effects of thermal stress and acrolein on permeability of MTE

7 monolayers. Therefore, we next examined if thermal stress and acrolein affect the paracellular pathway. We observed the structure and

8 distribution of the tight junction protein ZO-1 in MTE monolayers. In MTE monolayers, ZO-1 is one of the most widely studied scaffold

9 proteins and is uniformly expressed after an air-liquid interface is achieved (Umeda et al. 2006). Confocal microscopy showed that

0 thermal stress disrupted the integrity of ZO-1 (Fig. 8e) compared with the control group (Fig. 8b). Damage to the structure of ZO-1 was

1 also observed in acrolein-treated monolayers (Fig. 8h). Moreover, synergistic treatment of thermal stress and acrolein further exacerbated

2 the damage to ZO-1 (Fig. 8k) compared with thermal stress (Fig. 8e) or acrolein group (Fig. 8h). We quantified fluorescence intensity

3 and it was consistent with that from the representative confocal images (Fig. 8m). To determine the effects of thermal stress and acrolein

4 on cell detachment and death of MTE monolayers, we tested cell number and viability of monolayers post-thermal stress and after

5 acrolein. We found no significant cell detachment or death under these conditions (Fig. S4, all $P>0.05$ ). We examined expression of

6 occludin and claudins, but their expression levels were insufficient for visualization (Fig. S6). The FITC-dextran assay was performed

7 to further determine the effects of thermal stress and acrolein on paracellular permeability of MTE monolayers. We found that thermal

8 stress and acrolein significantly increased the permeability of MTE monolayers to FITC-dextran (Fig. S6p, $P<0.001$ ).

0 Discussion

1 Smoke inhalation injury is the main cause of death during a fire, and it is an important risk factor for increasing morbidity and

2 mortality (You et al. 2014). Pathogenic factors in inhalation injury, such as heat and toxic chemicals, cause direct injury to the airway

3 epithelial barrier. In this study, we aimed to investigate the effects of thermal stress and acrolein on permeability of the airway epithelial

4 barrier. MTE cells were isolated from mouse trachea and used to culture the model of the air-liquid interface (MTE monolayers). This 
5 in vitro model mainly contained goblet and cilia cells and imitated the physiological state of the normal airway epithelium (Hou et al.

6 2019). MTE monolayers are suitable for studying respiratory diseases, and they have been applied in toxicology, respiratory tract

7 infection, ion transport, cell carcinogenesis, and other experiments (Davidson et al. 2000; Horani et al. 2013). In our study, RTE and ISC

8 were markedly changed in thermal stress or acrolein-treated MTE monolayers. The changes in RTE and IsC caused by thermal stress or

9 acrolein were related to the transcellular pathway, which was mediated by ENaCs, CFTR, and $\mathrm{Na}^{+} / \mathrm{K}^{+}$-ATPase. Additionally, thermal

0 stress or acrolein regulated the paracellular pathway, which was mediated by tight junctions. These findings suggest the potential roles

1 of the transcellular and paracellular pathways in thermal stress or acrolein in damaging the airway epithelial barrier. Our findings may

2 provide new directions for the understanding, diagnosis, and treatment of smoke inhalation injury.

3 Transcellular and paracellular pathways are two essential determinants of RTE and ISC. In the current study, during thermal stress,

$4 \quad \mathrm{R}_{\mathrm{TE}}$ and ISC of MTE monolayers were changed in a two-phase (P1 and P2) manner. IsC was increased at P1, which could have been due

5 to enhanced ion transport by thermal stress. Concurrently, increased permeability led to a reduction in $\mathrm{R}_{\mathrm{TE}}$. The reverse change in $\mathrm{R}_{\mathrm{TE}}$

6 and ISC indicated that monolayers at P1 still had normal physiological characteristics. Subsequently, RTE and ISC were decreased at P2.

7 These findings could have resulted from damaged gap and tight junctions, which were shown by confocal images. Another explanation

8 for our findings is ion diffusion across MTE monolayers upon depletion of ATP. Therefore, we speculate that effects caused by thermal

9 stress are reversible at P1 and irreversible at P2. A previous study provided the basis for our speculation (Tobey et al. 1999) in which

0 increased ISC and decreased $\mathrm{R}_{\mathrm{TE}}$ were observed during application of heat to the esophageal epithelium, and recovery was observed

1 when the temperature returned to $37^{\circ} \mathrm{C}$. Cell death and detachment cause increased permeability of monolayers. However, our data from

2 cell counting and viability ruled out this possibility. To overcome the difference between species, we cultured HBE monolayers and

3 monitored $\mathrm{R}_{\mathrm{TE}}$ and $\mathrm{I}_{\mathrm{SC}}$. We found that $\mathrm{R}_{\mathrm{TE}}$ of HBE monolayers was decreased by thermal stress, which was similar to the result from

4 MTE monolayers. In contrast, thermal stress increased Isc of HBE monolayers to a high and stable level, which was similar to P1 in

5 MTE monolayers. However, we could not monitor the decreased trace of Isc (i.e., P2 in MTE monolayers). These findings indicated that

6 HBE monolayers showed lower thermal sensitivity and higher thermal resistance than primary MTE monolayers. 
$8 \quad \mathrm{P} 1$ and a declined trace at $\mathrm{P} 2$ when the temperature was gradually raised to $40^{\circ} \mathrm{C}$ from $37^{\circ} \mathrm{C}$. However, under the condition of a steady-

9 state at $40^{\circ} \mathrm{C}$, an elevated and stable IsC trace was visualized instead of two phases. In a previous study, researchers found elevated stable

$0 \quad$ Isc levels of rabbit esophageal epithelium in an Ussing chamber system in which the temperature had already been set to $49^{\circ} \mathrm{C}(\mathrm{Tobey}$

1 et al. 1999). These divergent responses in ISC and RTE to different time courses of thermal stress could be due to the response of the

2 individual transport system to thermal stress. Host cell adaption to environmental stress could explain the diverse observations between

3 the two procedures of thermal stress.

4 The paracellular and transcellular pathways are vital for establishing or dissipating ion concentration gradients and thus are important

5 for determining the ionic composition of the apical compartment and net volume flow (Flynn et al. 2009). Therefore, both pathways

6 work in concert and are functionally matched to meet the transport requirements of the specific tissue. The paracellular pathway is

7 mainly formed by tight junctions, and this pathway is located near the apical side of the cells and the lateral intercellular space (Tsukita

8 and Furuse 2002; Van Itallie and Anderson 2006). Tight junctions form the functional and structural boundary that separates apical and

9 basolateral compartments and also determine the ion transport properties of the paracellular pathway. Tight junctions are composed of

0 a complex of proteins that determine ion selectivity and conductance of the paracellular pathway (Farquhar and Palade 1963). ZO-1 is

1 one of the most widely studied tight junction protein (Umeda et al. 2006) and is uniformly expressed after the air-liquid interface is

2 achieved (Kuroishi et al. 2009). We found that thermal stress or acrolein decreased ZO-1 expression and disrupted its tight structure,

3 which indicated that thermal stress or acrolein regulated the paracellular ion transport pathway. Inhibitors (e.g., Amiloride, ouabain and

4 CFTRinh-172) can only block ion channels and transporters that belong to the transcellular pathway and inhibit the function of ion

5 transport. Therefore, inhibitors for ENaCs, CFTR, and $\mathrm{Na}^{+} / \mathrm{K}^{+}$-ATPase might not significantly affect these proteins. In our study, the

6 FITC-dextran flux assay showed increased FITC-dextran permeability in thermal stress or acrolein-treated MTE monolayers. Thermal

7 stress or acrolein not only damaged the complete structure of the tight junction but also increased its permeability.

8 In the current study, when adding acrolein to an apical bath solution, the bath solution was blown up to 10 times to ensure even 
9 distribution of acrolein instead of gas bubbling. Maintaining bubbling of a bath solution facilitates loss of acrolein. This situation was

0 supported by our results for comparing two experimental conditions with and without air bubbling (Fig. S5). A total of $500 \mu \mathrm{M}$ acrolein

1 adversely affected the integrity of the airway epithelial barrier, which was supported by a reduction in $\mathrm{R}_{\mathrm{TE}}$ and $\mathrm{ISC}_{\mathrm{SC}}$ a disrupted ZO-1

2 structure, as shown by confocal images, and the increased FITC-dextran permeability in MTE monolayers. Therefore, $500 \mu \mathrm{M}$ acrolein

3 caused irreversible damage to the airway epithelial barrier. Through a fitted RTE/Isc dose-response curve for acrolein in MTE monolayers,

4 we found that the $K_{\mathrm{i}}$ value for acrolein was lower at $40^{\circ} \mathrm{C}$ than at $37^{\circ} \mathrm{C}$. Therefore, the same dose of acrolein caused more serious damage

5 to $\mathrm{R}_{\mathrm{TE}} / \mathrm{ISC}_{\mathrm{SC}}$ under thermal stress conditions compared with $37^{\circ} \mathrm{C}$. Moreover, the damage to the integrity and permeability of tight junctions

6 caused by acrolein was more severe at $40^{\circ} \mathrm{C}$ than at $37^{\circ} \mathrm{C}$. The synergistic effects of thermal stress and acrolein induced further

7 impairment to the airway epithelial barrier. Our previous studies indicated that oxidative aldehydes, including formaldehyde and

8 crotonaldehyde, inhibited activity of ENaCs by causing activation of reactive oxygen species (ROS) in alveolar epithelium cell

9 monolayers (Cui et al. 2016; Li et al. 2017). Modulation of antioxidant enzymes affected the thermal sensitivity of respiratory cells.

0 Additionally, lowering superoxide dismutase enzyme levels resulted in a significant reduction in thermal resistance (Omar et al. 1987).

1 However, overexpression of manganese superoxide dismutase by stable transfection provided cellular resistance against the cytotoxic

2 effect of hyperthermia (Li and Oberley 1997; Kuninaka et al. 2000). Therefore, the synergistic effects of thermal stress and acrolein in

3 the present study may have resulted from increased thermal sensitivity to cells, which was caused by acrolein-activated oxidative

4 signaling.

5 As mentioned above, damage to the airway epithelium due to acrolein mainly results from its downstream signal via cellular

6 oxidative stress, such as glutathione depletion, and subsequently ROS stimulation (Wang et al. 2009). In addition to ENaCs, Na $/ \mathrm{K}^{+}-$

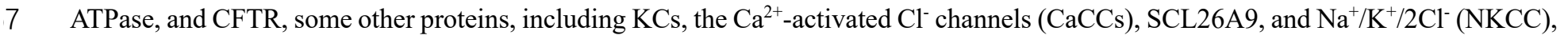

8 play roles in ion transport in the respiratory epithelium. Additionally, these proteins may be regulated by acrolein by induction of

9 oxidative stress (Londino et al. 2017). As the major $\mathrm{Ca}^{2+}$-activated $\mathrm{KCs}$ of ciliated cells, $\mathrm{K}_{\mathrm{Ca}} 1.1 / \mathrm{KCNMA} 1$ plays a role in maintaining

0 fluid secretion and is affected by oxidative stress (Manzanares et al. 2011; Kis et al. 2016; Hermann et al. 2015). Moreover, exposure to 
1 tobacco smoke inhibits $\mathrm{K}_{\mathrm{Ca}} 1.1 / \mathrm{KCNMA1}$ and results in a reduction in airway surface liquid in human bronchial epithelial cells (Sailland

2 et al. 2017). Anoctamin 6 functions as a CaCCs, and a $\mathrm{Ca}^{2+}$-dependent phospholipid scramblase, which are stimulated by an increase in

3 ROS and subsequent peroxidation of membrane lipids (Schreiber and Ousingsawat 2018; Scudieri et al. 2015). NKCC is located on the

4 basolateral membrane of the tracheal epithelium and is an important conduit for $\mathrm{Cl}^{-}$entry in the liquid-transporting epithelium (Gillie et

5 al. 2001). A previous study reported that NKCC activation may contribute to the protective system against ROS-mediated damage to

6 the airway epithelium (Matsuno et al. 2008). These studies may provide proof of acrolein damaging KCs, CaCCs, and NKCC in the

7 airway epithelium.

8 In addition to the effects of smoke inhalation on the tracheal epithelium, we also found interactions between different ion transport

9 systems. Apical and basolateral ion transport systems play diverse roles in the relationship between $\mathrm{R}_{\mathrm{TE}}$ and ISC. In our study, blockade

0 of $\mathrm{Na}^{+}$entry or $\mathrm{Cl}^{-}$secretion via apical ENaCs and CFTR, respectively, caused a reciprocal change in $\mathrm{R}_{\mathrm{TE}}$ and ISC. In contrast, inhibition

1 of basolateral $\mathrm{Na}^{+} / \mathrm{K}^{+}$-ATPase resulted in a reduction in $\mathrm{R}_{\mathrm{TE}}$ and Isc. Additionally, a $\mathrm{Cl}^{-}$-free solution showed a similar effect as ouabain

2 in inhibiting Isc. This finding indicates the potential dependence of $\mathrm{Na}^{+} / \mathrm{K}^{+}$-ATPase on anion transport or interactions between vertical

$3 \mathrm{Cl}^{-}$and $\mathrm{K}^{+}$transporters. This interesting similar effect can be excluded for the associations between $\mathrm{Cl}^{-}$and $\mathrm{Na}^{+}$transporters, because a

$4 \quad \mathrm{Na}^{+}$-free solution led to an opposite effect on RTE and Isc. Our study showed that the apical ENaCs and CFTR modulated RTE.

5 There are some limitations to this study, which need to be addressed in the future. Although the MTE in vitro model imitates the

6 physiological state and complies with the morphological characteristics of the normal airway epithelium, there are still some differences

7 from the in vivo environment. However, an in vivo model does not allow us to precisely measure RTE and Isc. Future studies need to

8 focus on the effects of thermal stress or acrolein on inflammatory signal transduction pathways at the molecular level. In addition to the

9 oxidative stress pathway, the mitogen-activated protein kinase (MAPK) pathway appears to play a role in regulating the airway epithelial

0 barrier (Huang et al. 2016; Lee et al. 2018). A previous study suggested that MAPK Hog1 phosphorylation was activated to a peak at

1 approximately $5 \mathrm{~min}$ after heat shock, and phosphorylated Hog1 declined to the basal level at 30 min (Dunayevich et al. 2018).

2 Researchers reached a similar conclusion in another study, where they found that heat-activated MAPK signaling was elevated to a peak 
at $5 \mathrm{~min}$, and activation was weakened or even disappeared over time (Dong et al. 2015). In the present study, application of thermal

of thermal stress or acrolein-induced MAPK signaling.

Thermal stress and acrolein are the two main pathogenic factors of smoke inhalation injury. Our study suggests that these two factors

Authors' contributions Hong-Long Ji conceived study, designed experiments, edited manuscript, and approved submission. Jianjun

Hong-Guang Nie, and Zaixing Chen prepared manuscript.

\section{Compliance with ethical standards}

1 Conflict of interest No conflicts of interest, financial or otherwise, are declared by the authors.

Abbreviations ENaCs, epithelial $\mathrm{Na}^{+}$channels; CFTR, cystic fibrosis transmembrane regulator; $\mathrm{R}_{\mathrm{TE}}$, transepithelial resistance; Isc,

dimethyl sulfoxide; ZO-1, zonula occludens-1; P1, phase 1; P2, phase 2; ASI, amiloride-sensitive Isc; KCs, $\mathrm{K}^{+}$channels; ROS, reactive

oxygen species; CaCCs, $\mathrm{Ca}^{2+}$-activated $\mathrm{Cl}^{-}$channels; $\mathrm{NKCC}, \mathrm{Na}^{+} / \mathrm{K}^{+} / 2 \mathrm{Cl}^{-}$; MAPK, mitogen-activated protein kinase. 


\section{References}

Alexander NS, Blount A, Zhang S, Skinner D, Hicks SB, Chestnut M, et al. Cystic fibrosis transmembrane conductance regulator modulation by the tobacco smoke toxin acrolein. Laryngoscope. 2012;122:1193-7.

Alwis KU, deCastro BR, Morrow JC, Blount BC. Acrolein Exposure in U.S. Tobacco Smokers and Non-Tobacco Users: NHANES 2005-2006. Environ Health Perspect. 2015;123:1302-8.

Anthony TR, Joggerst P, James L, Burgess JL, Leonard SS, Shogren ES. Method development study for APR cartridge evaluation in fire overhaul exposures. Ann Occup Hyg. 2007;51:703-16.

Bein K, Leikauf GD. Acrolein - a pulmonary hazard. Mol Nutr Food Res. 2011;55:1342-60.

Borchers MT, Wert SE, Leikauf GD. Acrolein-induced MUC5ac expression in rat airways. Am J Physiol. 1998;274:L573-81.

Burcham PC, Raso A, Thompson CA. Intermediate filament carbonylation during acute acrolein toxicity in A549 lung cells: functional consequences, chaperone redistribution, and protection by bisulfite. Antioxid Redox Signal. 2010;12(3):337-47.

Chang J, Ding Y, Zhou Z, Nie HG, Ji HL. Transepithelial Fluid and Salt Re-Absorption Regulated by cGK2 Signals. Int J Mol Sci. 2018;19:E881.

Chen Z, Zhao R, Zhao M, Liang X, Bhattarai D, Dhiman R, et al. Regulation of epithelial sodium channels in urokinase plasminogen activator deficiency. Am J Physiol Lung Cell Mol Physiol. 2014;307:L609-17.

Cui Y, Li H, Wu S, Zhao R, Du D, Ding Y, et al. Formaldehyde impairs transepithelial sodium transport. Sci Rep. 2016;6:35857.

Davidson DJ, Kilanowski FM, Randell SH, Sheppard DN, Dorin JR. A primary culture model of differentiated murine tracheal epithelium. Am J Physiol Lung Cell Mol Physiol. 2000;279(4):L766-78.

Dong ZW, Chen J, Ruan YC, Zhou T, Chen Y, Chen Y, et al. CFTR-regulated MAPK/NF-kappaB signaling in pulmonary inflammation in thermal inhalation injury. Sci Rep. 2015;5:15946

Dubick MA, Carden SC, Jordan BS, Langlinais PC, Mozingo DW. Indices of antioxidant status in rats subjected to wood smoke inhalation and/or thermal injury. Toxicology. 2002;176(1-2):145-57.

Dunayevich P, Baltanas R, Clemente JA, Couto A, Sapochnik D, Vasen G, et al. Heat-stress triggers MAPK crosstalk to turn on the hyperosmotic response pathway. Sci Rep. 2018;8(1):15168.

Faroon O, Roney N, Taylor J, Ashizawa A, Lumpkin MH, Plewak DJ. Acrolein environmental levels and potential for human exposure. Toxicol Ind Health. 2008;24(8):543-64.

Farquhar MG, Palade GE. Junctional complexes in various epithelia. The Journal of cell biology. 1963;17:375-412. doi:10.1083/jcb.17.2.375.

Farquhar MG, Palade GE. Junctional complexes in various epithelia. The Journal of cell biology. 1963;17:375-412.

Fitzgerald KT, Flood AA. Smoke inhalation. Clin Tech Small Anim Prac. 2006;21:205-14.

Flynn AN, Itani OA, Moninger TO, Welsh MJ. Acute regulation of tight junction ion selectivity in human airway epithelia. Proc Natl Acad Sci U S A. 2009;106:3591-6.

Fuller CM, Benos DJ. CFTR! Am J Physiol. 1992;263:C267-86.

Gillie DJ, Pace AJ, Coakley RJ, Koller BH, Barker PM. Liquid and ion transport by fetal airway and lung epithelia of mice deficient in sodium-potassium-2-chloride transporter. Am J Respir Cell Mol Biol. 2001;25(1):14-20.

Hales CA, Barkin PW, Jung W, Trautman E, Lamborghini D, Herrig N, et al. Synthetic smoke with acrolein but not $\mathrm{HCl}$ produces pulmonary edema. J Appl Physiol (1985). 1988;64:1121-33.

Han DY, Nie HG, Gu X, Nayak RC, Su XF, Fu J, et al. K+ channel openers restore verapamil-inhibited lung fluid resolution and transepithelial ion transport. Respir Res. 2010;11:65.

Haponik EF. Clinical smoke inhalation injury: pulmonary effects. Occup Med. 1993;8:430-68.

Hermann A, Sitdikova GF, Weiger TM. Oxidative Stress and Maxi Calcium-Activated Potassium (BK) Channels. Biomolecules. 2015;5(3):1870-911.

Horani A, Dickinson JD, Brody SL. Applications of mouse airway epithelial cell culture for asthma research. Methods Mol Biol. 
2013;1032:91-107.

Hou Y, Cui Y, Zhou Z, Liu H, Zhang H, Ding Y, et al. Upregulation of the WNK4 Signaling Pathway Inhibits Epithelial Sodium Channels of Mouse Tracheal Epithelial Cells After Influenza A Infection. Front Pharmacol. 2019;10:12.

Howard M, Roux J, Iles KE, Miyazawa B, Christiaans S, Anjum N, et al. Activation of the heat shock response attenuates the interleukin 1beta-mediated inhibition of the amiloride-sensitive alveolar epithelial ion transport. Shock. 2013;39:189-96.

Huang W, Zhao H, Dong H, Wu Y, Yao L, Zou F, et al. High-mobility group box 1 impairs airway epithelial barrier function through the activation of the RAGE/ERK pathway. Int J Mol Med. 2016;37(5):1189-98.

Kis A, Krick S, Baumlin N, Salathe M. Airway Hydration, Apical K(+) Secretion, and the Large-Conductance, Ca(2+)-activated and Voltage-dependent Potassium (BK) Channel. Ann Am Thorac Soc. 2016;13 Suppl 2:S163-8.

Kuninaka S, Ichinose Y, Koja K, Toh Y. Suppression of manganese superoxide dismutase augments sensitivity to radiation, hyperthermia and doxorubicin in colon cancer cell lines by inducing apoptosis. Br J Cancer. 2000;83(7):928-34.

Kuroishi S, Suda T, Fujisawa T, Ide K, Inui N, Nakamura Y, et al. Epithelial-mesenchymal transition induced by transforming growth factor-beta1 in mouse tracheal epithelial cells. Respirology. 2009;14:828-37.

Lee KE, Jee HM, Hong JY, Kim MN, Oh MS, Kim YS, et al. German Cockroach Extract Induces Matrix Metalloproteinase-1 Expression, Leading to Tight Junction Disruption in Human Airway Epithelial Cells. Yunsei Med J. 2018;59(10):1222-31.

Li JJ, Oberley LW. Overexpression of manganese-containing superoxide dismutase confers resistance to the cytotoxicity of tumor necrosis factor alpha and/or hyperthermia. Cancer Res. 1997;57(10):1991-8.

Li Y, Chang J, Cui Y, Zhao R, Ding Y, Hou Y, et al. Novel mechanisms for crotonaldehyde-induced lung edema. Oncotarget. 2017;8:83509-22.

Londino JD, Lazrak A, Collawn JF, Bebok Z, Harrod KS, Matalon S. Influenza virus infection alters ion channel function of airway and alveolar cells: mechanisms and physiological sequelae. Am J Physiol Lung Cell Mol Physiol. 2017;313(5):L845-158.

Manzanares D, Gonzalez C, Ivonnet P, Chen RS, Valencia-Gattas M, Conner GE, et al. Functional apical large conductance, Ca2+activated, and voltage-dependent $\mathrm{K}+$ channels are required for maintenance of airway surface liquid volume. J Biol Chem. 2011;286(22):19830-9.

Matsuno T, Ito Y, Ohashi T, Morise M, Takeda N, Shimokata K, et al. Dual pathway activated by tert-butyl hydroperoxide in human airway anion secretion. J Pharmacol Exp Ther. 2008;327(2):453-64.

Meacher DM, Menzel DB. Glutathione depletion in lung cells by low-molecular-weight aldehydes. Cell Biol Toxicol. 1999;15:163-71. Nie HG, Chen L, Han DY, Li J, Song WF, Wei SP, et al. Regulation of epithelial sodium channels by cGMP/PKGII. J Physiol. 2009;587:2663-76

Omar RA, Yano S, Kikkawa Y. Antioxidant enzymes and survival of normal and simian virus 40-transformed mouse embryo cells after hyperthermia. Cancer Res. 1987;47(13):3473-6.

Reinhardt TE, Ottmar RD. Baseline measurements of smoke exposure among wildland firefighters. J Occup Environ Hyg. 2004;1:593606.

Romet-Haddad S, Marano F, Blanquart C, Baeza-Squiban A. Tracheal epithelium in culture: a model for toxicity testing of inhaled molecules. Cell Biol Toxicol. 1992;8:141-50.

Roux E, Ouedraogo N, Hyvelin JM, Savineau JP, Marthan R. In vitro effect of air pollutants on human bronchi. Cell Biol Toxicol. 2002;18:289-99.

Sailland J, Grosche A, Baumlin N, Dennis JS, Schmid A, Krick S, et al. Role of Smad3 and p38 Signalling in Cigarette Smoke-induced CFTR and BK dysfunction in Primary Human Bronchial Airway Epithelial Cells. Sci Rep. 2017;7(1):10506.

Schreiber R, Ousingsawat J. Regulation of TMEM16A/ANO1 and TMEM16F/ANO6 ion currents and phospholipid scrambling by $\mathrm{Ca}(2+)$ and plasma membrane lipid. J Physiol. 2018;596(2):217-29.

Scudieri P, Caci E, Venturini A, Sondo E, Pianigiani G, Marchetti C, et al. Ion channel and lipid scramblase activity associated with expression of TMEM16F/ANO6 isoforms. J Physiol. 2015;593(17):3829-48.

Sheppard DN, Welsh MJ. Structure and function of the CFTR chloride channel. Physiol Rev. 1999;79:S23-45. 
6 Stevens JF, Maier CS. Acrolein: sources, metabolism, and biomolecular interactions relevant to human health and disease. Mol Nutr 17 Food Res. 2008;52:7-25.

8 Tobey NA, Sikka D, Marten E, Caymaz-Bor C, Hosseini SS, Orlando RC. Effect of heat stress on rabbit esophageal epithelium. Am J 9 Physiol. 1999;276:G1322-30.

0 Tsukita S, Furuse M. Claudin-based barrier in simple and stratified cellular sheets. Curr Opin Cell Biol. 2002;14:531-6.

1 Umeda K, Ikenouchi J, Katahira-Tayama S, Furuse K, Sasaki H, Nakayama M, et al. ZO-1 and ZO-2 independently determine where 2 claudins are polymerized in tight-junction strand formation. Cell. 2006;126:741-54.

3 Van Itallie CM, Anderson JM. Claudins and epithelial paracellular transport. Annu Rev Physiol. 2006;68:403-29.

4 Wang T, Liu Y, Chen L, Wang X, Hu XR, Feng YL, et al. Effect of sildenafil on acrolein-induced airway inflammation and mucus 5 production in rats. European Respir J. 2009;33(5):1122-32.

6 Wang X, Adler KB, Erjefalt J, Bai C. Airway epithelial dysfunction in the development of acute lung injury and acute respiratory distress 7 syndrome. Expert Rev Respir Med. 2007;1:149-55.

8 Wang Y, Bai C, Li K, Adler KB, Wang X. Role of airway epithelial cells in development of asthma and allergic rhinitis. Respir Med. $9 \quad 2008 ; 102: 949-55$.

0 You K, Yang HT, Kym D, Yoon J, HaejunYim, Cho YS, et al. Inhalation injury in burn patients: establishing the link between diagnosis 1 and prognosis. Burns. 2014;40:1470-5. 
Figure Legends

Fig. 1 Thermal stress alternates bioelectric features in mouse tracheal epithelial (MTE) and human bronchial epithelial (HBE)

monolayers. (a) Representative transepithelial resistance ( $\left.\mathrm{R}_{\mathrm{TE}}\right)$ trace in MTE monolayer mounted on an Ussing chamber setup. $\mathrm{R}_{\mathrm{TE}}$ was the ExpDec1 function. $\left(y_{0}=0.36 \pm 0.04, A=0.87 \pm 0.04[\mathrm{P} 1] ; y_{0}=-0.87 \pm 0.11, A=3.22 \pm 0.36[\mathrm{P} 2]\right)$. Student's t-test. ${ }^{* * *} P<0.001 . n$

= 12. (f) Representative $\mathrm{R}_{\mathrm{TE}}$ trace in HBE monolayer. $\mathrm{R}_{\mathrm{TE}}$ was decreased during the temperature of the bath solution was elevated to

$140^{\circ} \mathrm{C}$ (red line) from $37^{\circ} \mathrm{C}$ (black line). (g) Isc trace recorded simultaneously in the same HBE monolayer. Isc was increased to a high

2 and stable level during thermal stress. (h) Average RTE levels of HBE monolayers under the conditions of $37^{\circ} \mathrm{C}$ and $40^{\circ} \mathrm{C}$. Student's t-

test. NS, no significance. $n=6$. (i) Average Isc levels of HBE monolayers. Student's t-test. ${ }^{*} P<0.05 . n=6$.

Fig. $2 \mathrm{Na}^{+}$transport mediates thermal stress-induced bioelectric changes in MTE monolayers. (a, b) Representative $\mathrm{R}_{\mathrm{TE}}$ and ISC 

sensitive Isc levels at P2 ( $\triangle \mathrm{I}_{\mathrm{SC}}$, the difference between the peak IsC and the ending IsC at P2). Student's t-test. ${ }^{* * *} P<0.001 . n=20$.

Fig. 3 CFTR is involved in thermal stress-induced bioelectric changes in MTE monolayers (a, b) Representative RTE and IsC traces in the presence of saline bath solution (control group, solid line) and CFTRinh-172 (CFTRinh, $20 \mu \mathrm{M}$, dashed line). Segments of traces recorded at different bath temperatures were shown as black $\left(37^{\circ} \mathrm{C}\right)$ and red lines $\left(40^{\circ} \mathrm{C}\right)$. Arrows indicated the time to add CFTRinh172. When the temperature rose to $38.5^{\circ} \mathrm{C}$, the obvious bioelectric changes were observed. (c) Average thermal stress-sensitive $\mathrm{R}_{\mathrm{TE}}$ levels $\left(\triangle \mathrm{R}_{\mathrm{TE}}\right.$, the difference between the initial $\mathrm{R}_{\mathrm{TE}}$ and ending $\mathrm{R}_{\mathrm{TE}}$ within one phase [P1 or P2]). Student's t-test. ${ }^{* *} P<0.01$ and ${ }^{* * *} P<$

$10.001 . n=18$. (d) Average thermal stress-sensitive IsC levels at P1 ( $\triangle \mathrm{I}_{\mathrm{SC}}$, the difference between the basal $\mathrm{I}_{\mathrm{SC}}$ and the peak ISC at P1).

2 Student's t-test. ${ }^{*} P<0.05 . n=9$. (e) Average thermal stress-sensitive Isc levels at P2 $(\triangle \mathrm{Isc}$, the difference between the peak Isc and the 3 ending ISC at P2). Student's t-test. ${ }^{*} P<0.05 . n=9$.

Fig. 4. Activation of ENaCs, CFTR, and $\mathrm{Na}^{+}-\mathrm{K}^{+}$-ATPase of MTE monolayers by thermal stress. (a, c, and e) Representative Isc traces before and after the addition of amiloride $(100 \mu \mathrm{M})$, CFTRinh $(20 \mu \mathrm{M})$, or ouabain $(1 \mathrm{mM})$ at $37^{\circ} \mathrm{C}$ (black lines) and $40^{\circ} \mathrm{C}($ red lines). Arrows indicated the time to add inhibitors. (b, d and f) Average IsC levels. Total ISC meant the basal ISC level; +Amil IsC,

8 +CFTRinh Isc, and +Ouabain Isc meant inhibitor-resistant Isc level; ASI (amiloride-sensitive Isc), CFTRinh Isc and Ouabain Isc 9 respectively reflected the activity of each ion channel and was calculated by the difference between the basal Isc and inhibitor-resistant $0 \quad$ ISC. Student's t-test and Mann-Whitney U test. ${ }^{*} P<0.05$ and ${ }^{* *} P<0.01$. NS, no significance. $n=18$. (g) Average RTE levels. Student's t1 test and Mann-Whitney U test. ${ }^{*} P<0.05$ and ${ }^{* * *} P<0.001$. NS, no significance. $n=36$. 

acrolein was $125.89 \mu \mathrm{M}$ at $37^{\circ} \mathrm{C}$ and $112.21 \mu \mathrm{M}$ at $40^{\circ} \mathrm{C}$, respectively.

Fig. $6 \mathrm{Na}^{+}$transport is involved in acrolein-impaired bioelectric features in MTE monolayers. (a, b) Representative RTE and ISC

levels $\left(\triangle \mathrm{R}_{\mathrm{TE}}\right.$, the difference between basal $\mathrm{R}_{\mathrm{TE}}$ and acrolein-resistant $\left.\mathrm{R}_{\mathrm{TE}}\right)$. Mann-Whitney $\mathrm{U}$ test. ${ }^{*} P<0.05 . n=16$. (d) Average acrolein-

16.

Fig. 7 CFTR mediates acrolein-impaired bioelectric features in MTE monolayers. (a, b) Representative RTE and ISC traces in the presence of saline bath solution (control group, solid lines) and CFTRinh-172 (20 $\mu \mathrm{M}$, dashed lines). Arrows showed the time for adding CFTRinh-172. Then monolayers were exposed to $500 \mu \mathrm{M}$ acrolein (ACR, blue lines). (c) Average acrolein-sensitive $\mathrm{R}_{\mathrm{TE}}$ levels $\left(\triangle \mathrm{R}_{\mathrm{TE}}\right.$, 
$6\left(\triangle \mathrm{I}_{\mathrm{SC}}\right.$, the difference between basal ISC and acrolein-resistant $\left.\mathrm{I}_{\mathrm{SC}}\right)$. Student's t-test. ${ }^{* * *} P<0.001 . n=11$.

8 Fig. 8 The synergistic effects of thermal stress and acrolein on ZO-1 tight junction in MTE monolayers. Laser scanning confocol

9 imaging for ZO-1 protein in MTE monolayers treated by $37^{\circ} \mathrm{C} \mathrm{(a-c),} 40^{\circ} \mathrm{C}$ for $120 \mathrm{~min}(\mathbf{d}-\mathbf{f}), 500 \mu \mathrm{M}$ acrolein $(\mathbf{g}-\mathbf{i})$, and combination of

$0 \quad 40^{\circ} \mathrm{C}$ and $500 \mu \mathrm{M}$ acrolein (j-l). Nucleus was labeled with hoechst (blue), and tight junction was labeled with ZO-1 (green). Scale bar:

$150 \mu \mathrm{m}$. (m) Quantification of ZO-1 fluorescence intensity. Student's t-test. ${ }^{*} P<0.05,{ }^{* * *} P<0.001,{ }^{\&} P<0.05$ and ${ }^{\sharp} P<0.05 . n=12$. 


\title{
Supplementary materals
}

\section{Ion transport mechanisms for smoke inhalation injured airway epithelial barrier}

\author{
Jianjun Chang, Zaixing Chen ${ }^{\star}$, Runzhen Zhao, Hong-Guang Nie, Hong-Long Ji
}

\section{Supplemental Figure LegendsFig. S1 Extreme thermal stress disrupts bioelectric features in minutes in mouse tracheal}

epithelial (MTE) monolayers. (a) Representative transepithelial resistance $\left(\mathrm{R}_{\mathrm{TE}}\right)$ trace at $37^{\circ} \mathrm{C}, 42^{\circ} \mathrm{C}$, and $44^{\circ} \mathrm{C}$. $\mathrm{R}_{\mathrm{TE}}$ was

eliminated to zero at $44^{\circ} \mathrm{C}$. (b) Short-circuit current $\left(\mathrm{I}_{\mathrm{SC}}\right)$ trace recorded simultaneously of the same monolayer. At $44^{\circ} \mathrm{C}$, ISC was

decreased followed by a jump, probably because of the damage to tight monolayer. (c) Representative $\mathrm{R}_{\mathrm{TE}}$ trace at $37^{\circ} \mathrm{C}, 40^{\circ} \mathrm{C}$, and

$42^{\circ} \mathrm{C}$. R $\mathrm{TE}$ was eliminated to zero at $42^{\circ} \mathrm{C}$. (d) ISC trace of the same monolayer. IsC was decreased at $42^{\circ} \mathrm{C}$ and then shot up and out of

the scale in minutes probably due to impaired monolayer.

Fig. S2 Long process of apical and basolateral-permeabilizing destabilizes $\mathrm{R}_{\mathrm{TE}}$ and $\mathrm{I}_{\mathrm{SC}}$ measurements in MTE monolayers. (a)

Representative $\mathrm{R}_{\mathrm{TE}}$ traces of apical-permeabilized MTE monolayers. After long time of apical permeabilizing process, $\mathrm{R}_{\mathrm{TE}}$ was

decreased near zero. (b) Isc traces monitored synchronously of the same monolayers. Isc was reduced followed by a jump. (c)

Representative $\mathrm{R}_{\mathrm{TE}}$ traces of basolateral-permeabilized MTE monolayers. $\mathrm{R}_{\mathrm{TE}}$ was almost decreased to zero. (d) IsC traces of the same

monolayers. Isc was decreased and then out of the scale upwardly probably due to the damage to tight monolayers.

Fig. S3 Cl-free bath solution eliminates $\mathbf{R}_{\mathrm{TE}}$ and $\mathrm{ISC}_{\mathrm{SC}}$ levels in MTE monolayers. (a) Representative $\mathrm{R}_{\mathrm{TE}}$ trace in the presence of saline bath solution (control group, black line) and $\mathrm{Cl}^{-}$-free bath solution (green line). $\mathrm{Cl}^{-}$-free bath solution caused the transient increment followed by the slow decline of RTE. (b) Isc trace recorded synchronously of the same monolayer. (c) Average RTE levels. RTE was eliminated to $0.24 \pm 0.03 \mathrm{k} \Omega \times \mathrm{cm}^{2}$ compared with the control group $\left(0.91 \pm 0.05 \mathrm{k} \Omega \times \mathrm{cm}^{2}\right)$, probably due to impaired tight monolayers. Student's t-test. ${ }^{* * *} P<0.001 . n=8$. (d) Average Isc levels. Student's t-test. ${ }^{* * *} P<0.001 . n=8$. 
Fig. S4 Cell count and viability in MTE monolayers. (a) Cell number of monolayers post the exposure of thermal stress (120 min) and acrolein $(500 \mu \mathrm{M})$. Ten randomly selected images across the monolayers from at least 3 independent experiments were captured and counted for total cells with DAPI staining using a cell count plug-in of the ImageJ. No significant difference was observed among each group. Thermal stress and acrolein could not induce significant cell detachment of monolayers. NS, no significance. $n=12$. (b) Cell viability of monolayers treated by thermal stress $(120 \mathrm{~min})$ and acrolein $(500 \mu \mathrm{M})$. At the end of treatment, cell viability was measured with the cell counting kit-8 assay. Thermal stress and acrolein failed to cause obvious cell death of monolayers. NS, no significance. $n=12$.

Fig. S5 Comparison of the effects of acrolein on $\mathbf{I}_{\mathrm{SC}}$ and $\mathbf{R}_{\mathrm{TE}}$ in bubbled and unbubbled MTE monolayers. (a) Representative R trace when unbubbling (black line) or bubbling (red line). (b) Isc trace recorded simultaneously of the same monolayers. Keeping bubbling the bath solution facilitated the loss of acrolein and mitigated the effects of acrolein on RTE and IsC.

Fig. S6 Thermal stress and acrolein impair occludin tight junction of MTE monolayers. Laser scanning confocol imaging for occludin tight junction of MTE monolayers treated by $37^{\circ} \mathrm{C}(\mathbf{a}-\mathbf{c}), 40^{\circ} \mathrm{C}$ for $120 \mathrm{~min}(\mathbf{d}-\mathbf{f}), 500 \mu \mathrm{M}$ acrolein $(\mathbf{g}-\mathbf{i})$, and the combination of $40^{\circ} \mathrm{C}$ and $500 \mu \mathrm{M}$ acrolein (j-l). Nuclei were labeled with hoechst (blue), and tight junctions were labeled with occludin (green). Scale bar: $10 \mu \mathrm{m} . \mathbf{( m - o )}$ Immunolocalization of claudin tight junction of normal MTE monolayer. Nuclei were labeled with hoechst (blue), and tight junctions were labeled with claudin (green). The expression of claudin was insufficient to be visualized. Scale bar: 50 $\mu \mathrm{m}$. (p) Fluorescein isothiocyanate-dextran $(4 \mathrm{kDa})$ permeability assay of MTE monolayers. MTE monolayers were treated by $37^{\circ} \mathrm{C}$, $40^{\circ} \mathrm{C}$ for $120 \mathrm{~min}, 500 \mu \mathrm{M}$ acrolein, and the combination of $40^{\circ} \mathrm{C}$ and $500 \mu \mathrm{M}$ acrolein. Thermal stress and acrolein increased the permeability of fluorescein isothiocyanate-dextran. Student's t-test. ${ }^{* * *} P<0.001 . n=14$. 
Fig. S1

a

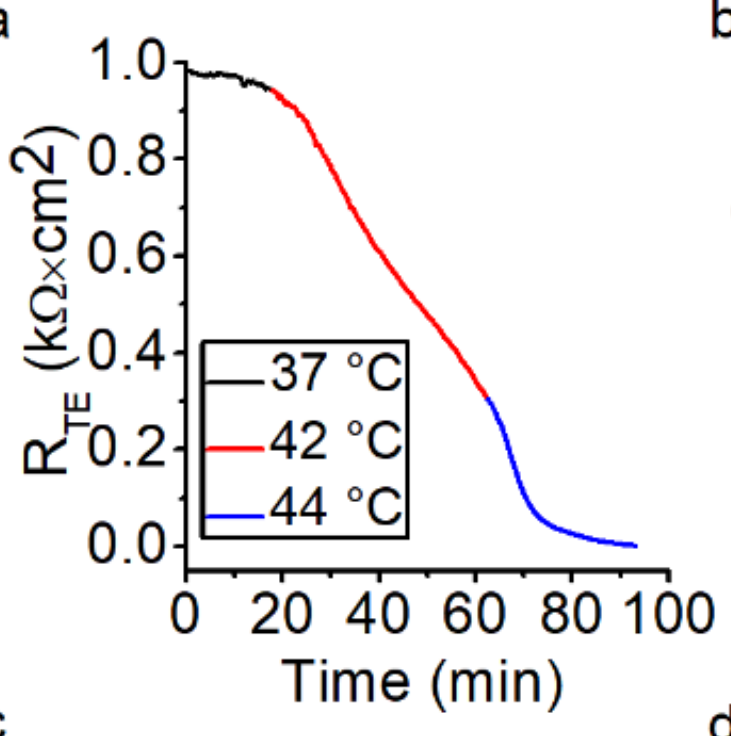

C

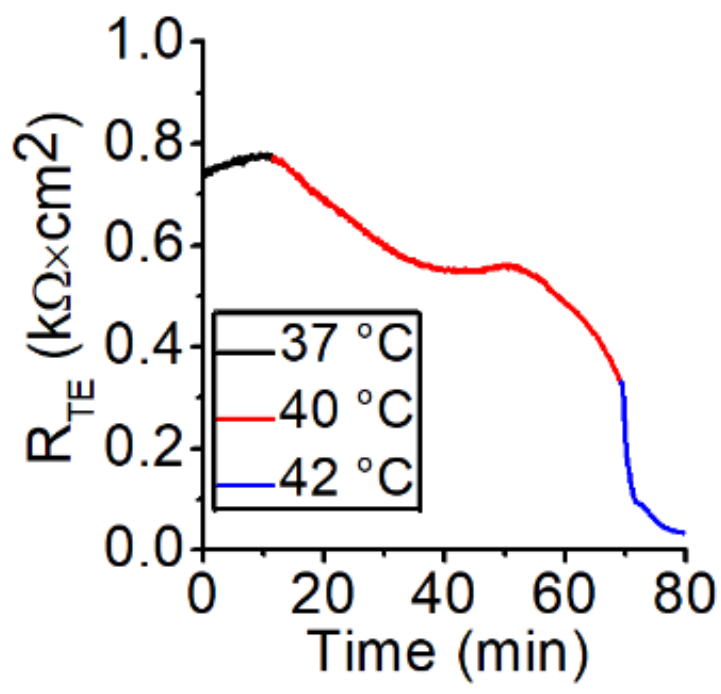

b

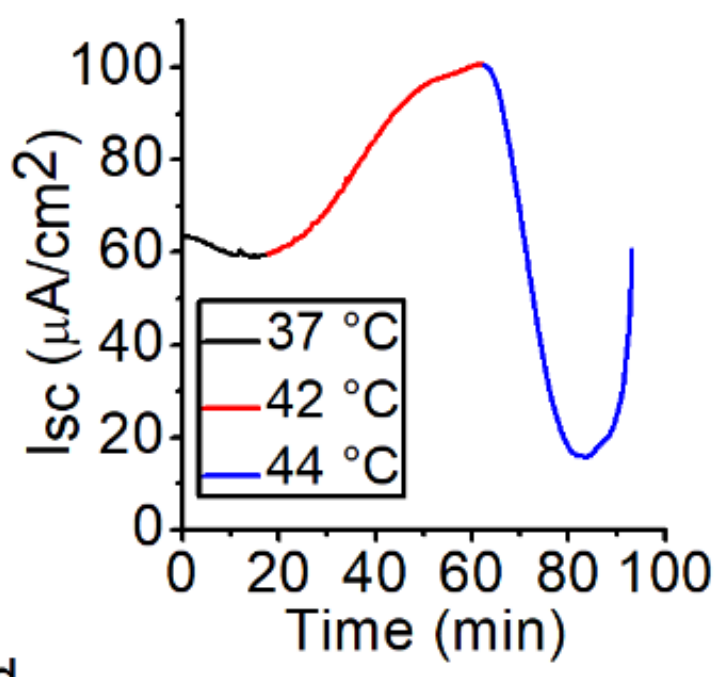

d

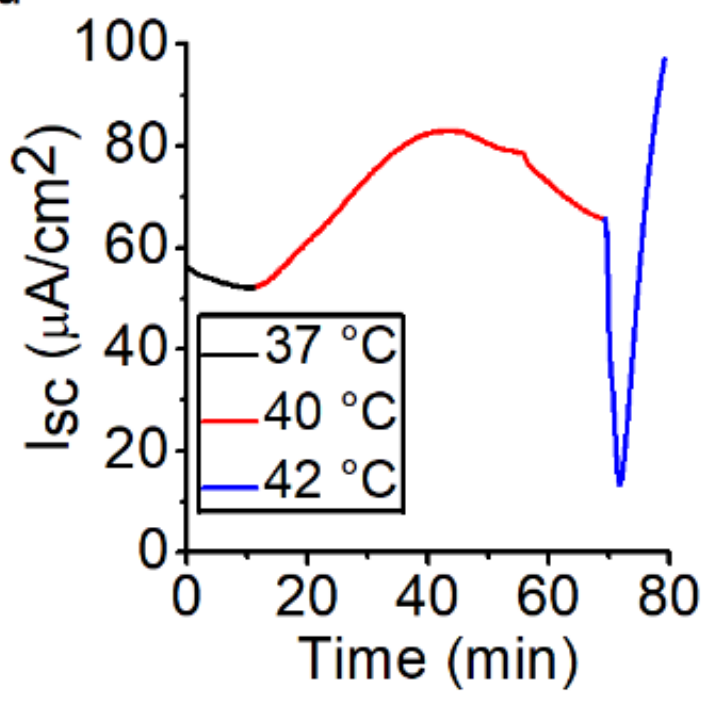


Fig. S2
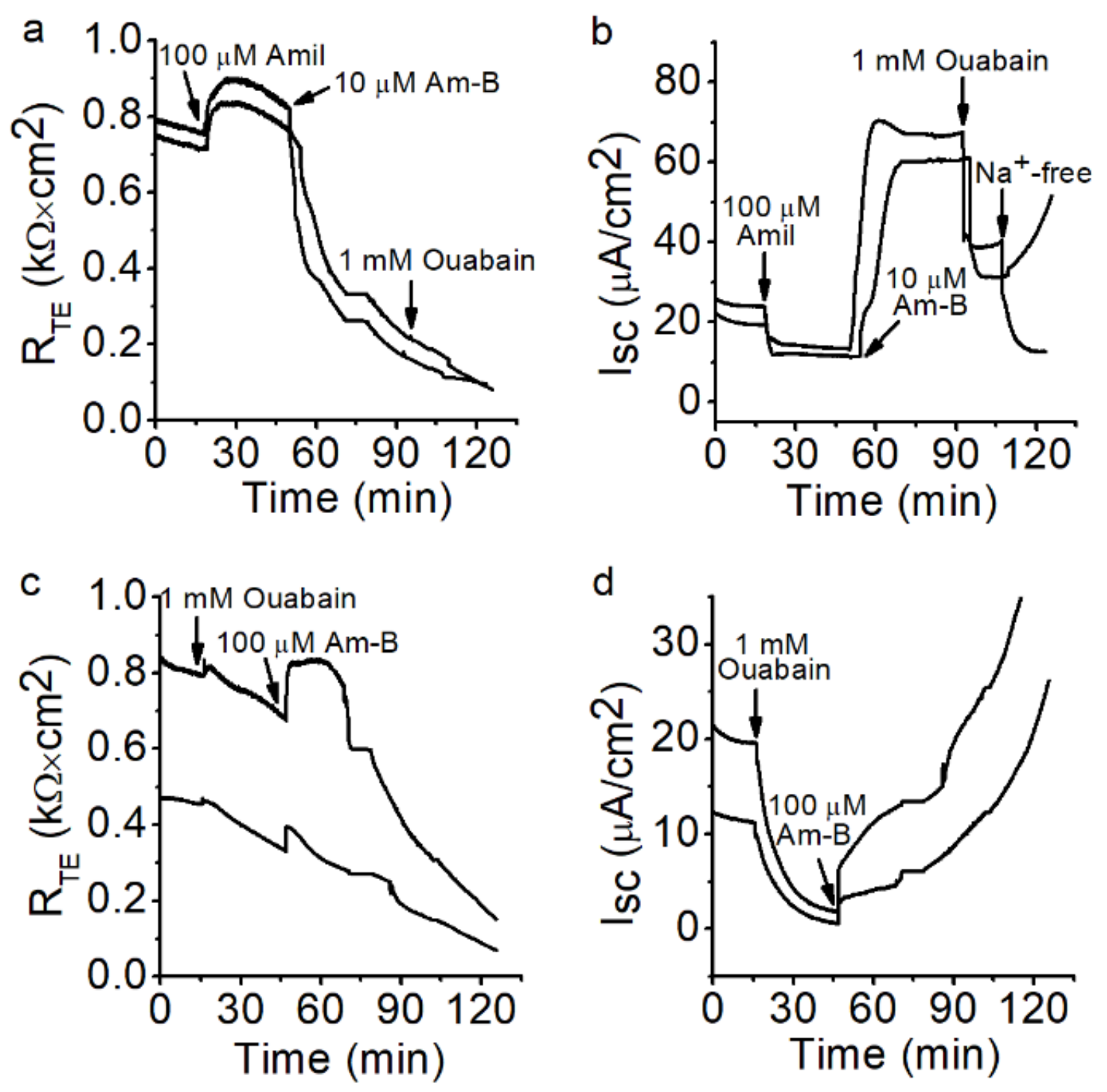
Fig. S3
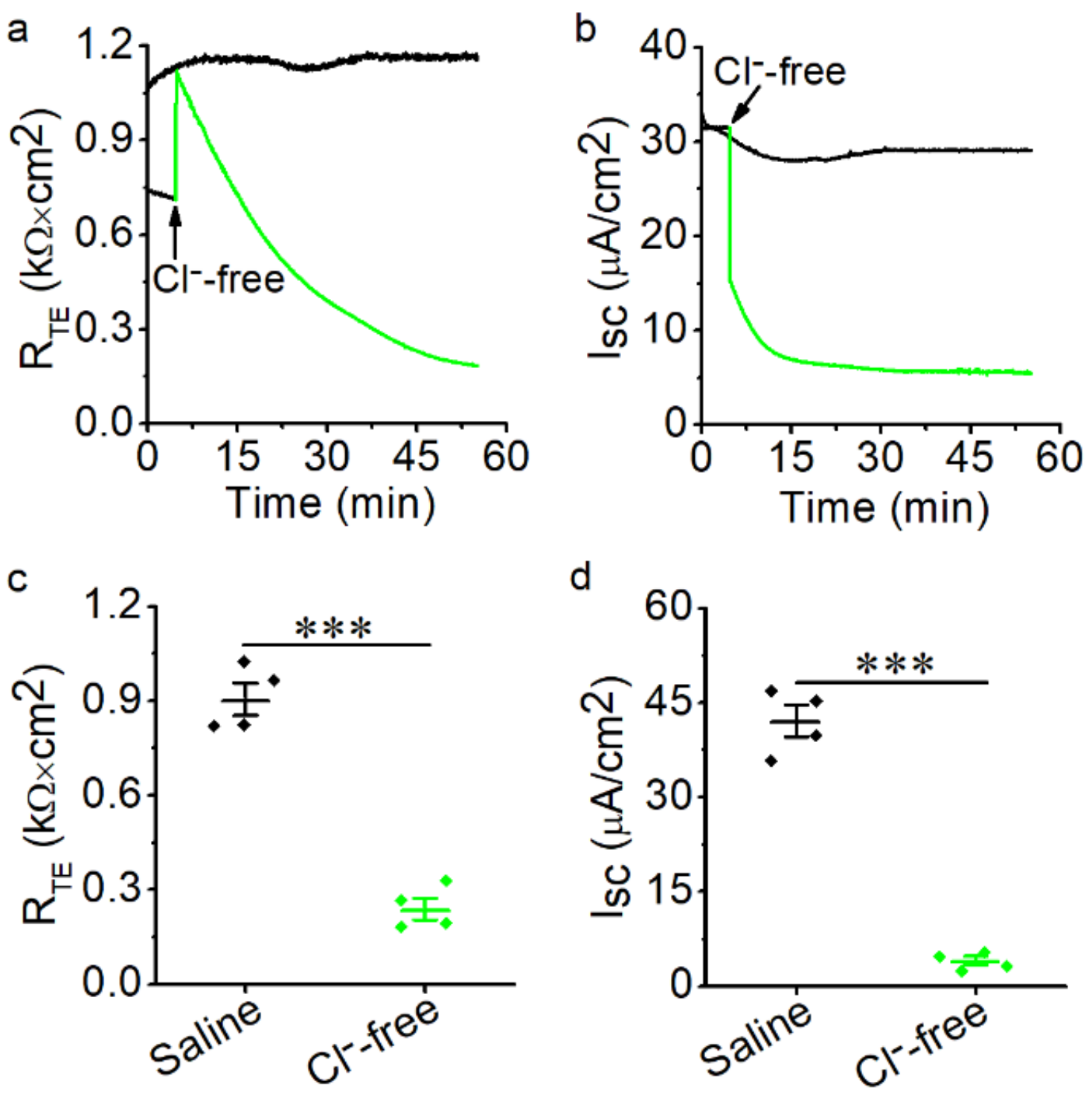
Fig. S4
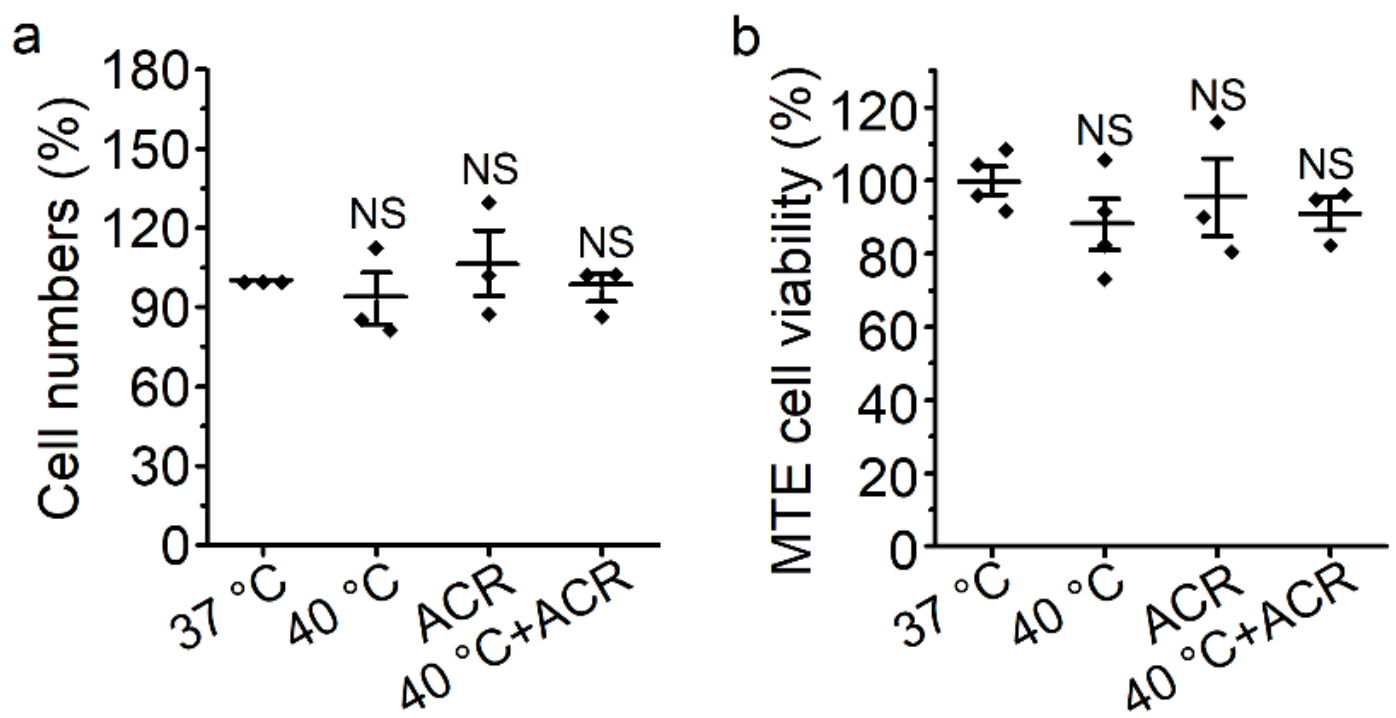
Fig. S5

a

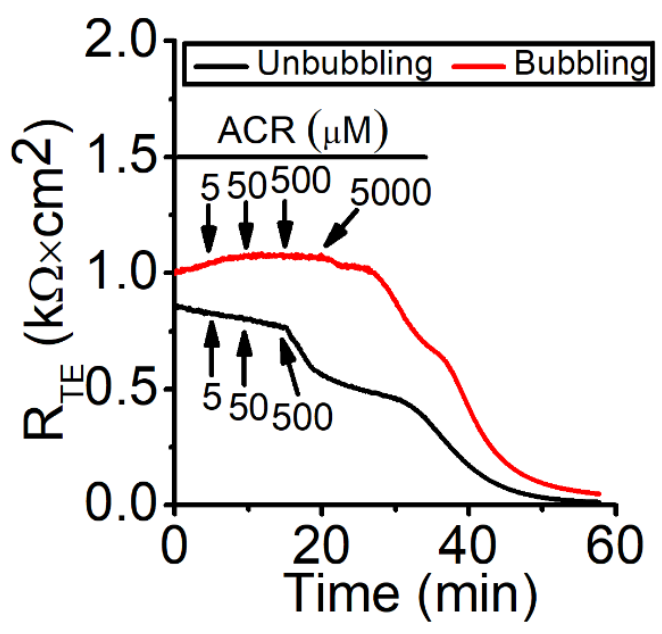

b

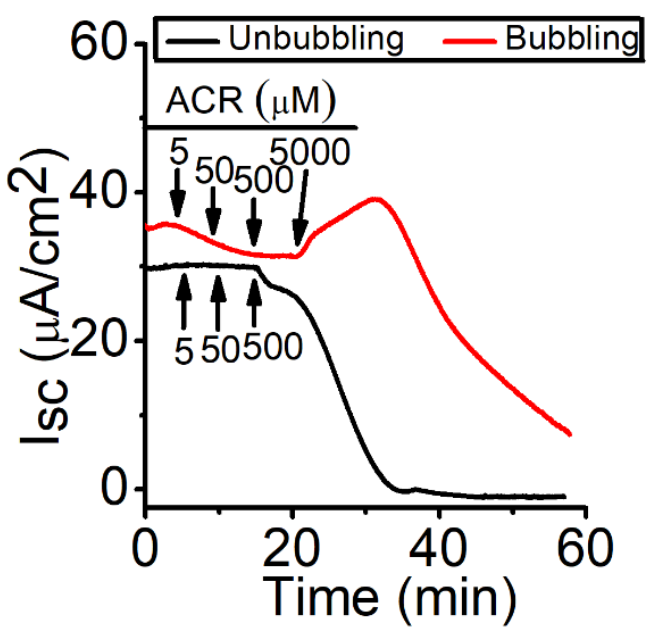


Fig. S6

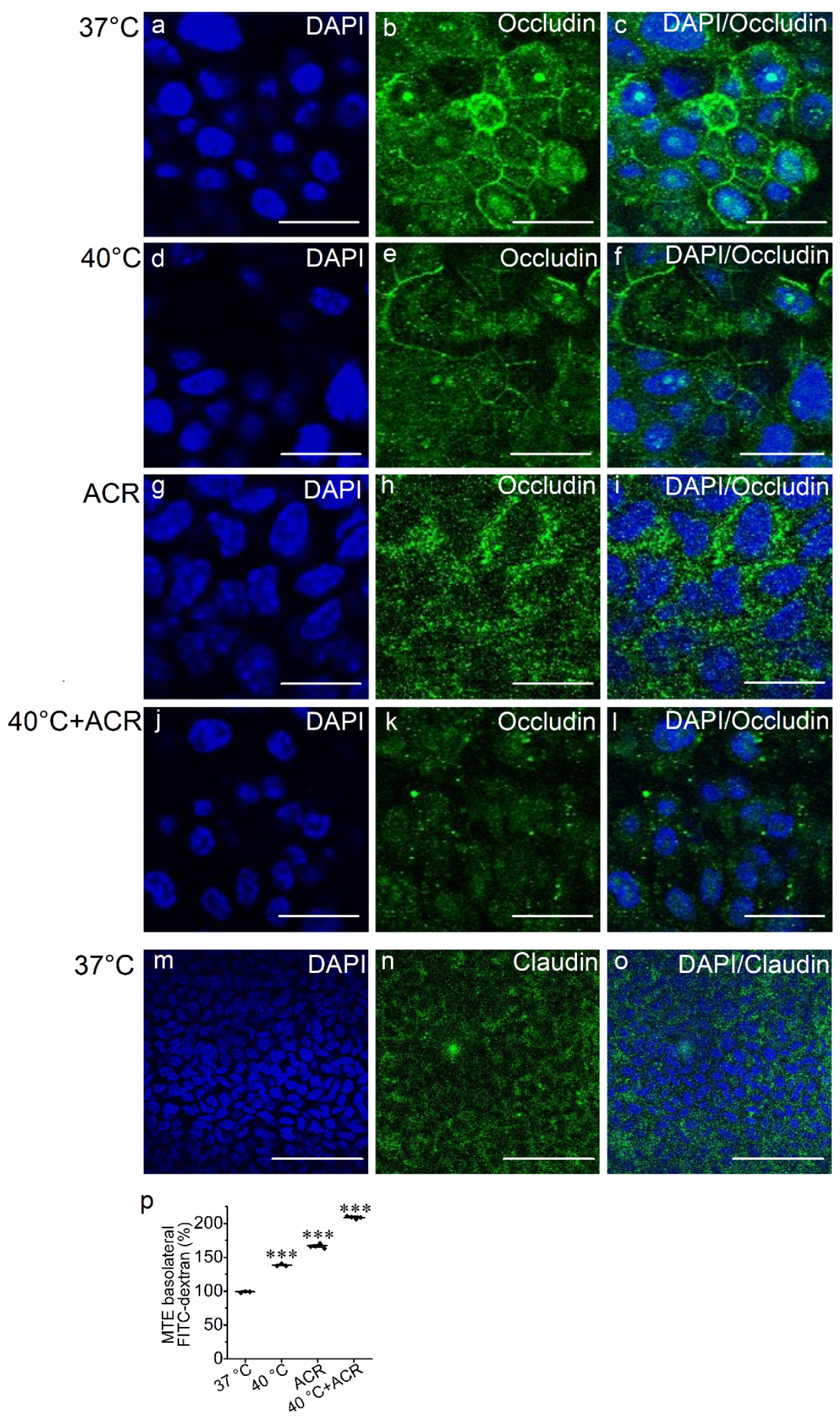


Supplemental data table 1. Parameters when RTE raw data were fitted by the ExpDec1 function

\begin{tabular}{|l|l|l|l|l|l|l|l|l|l|l|l|l|}
\hline Group & \multicolumn{9}{|c|}{ P1 } & \multicolumn{5}{c|}{ P2 } \\
\hline Sample number & 1 & 2 & 3 & 4 & 5 & 6 & 7 & 8 & 1 & 2 & 3 & 4 \\
\hline $\boldsymbol{y}_{0}$ & 0.34 & 0.46 & 0.52 & 0.097 & 0.30 & 0.35 & 0.36 & 0.42 & -0.89 & -1.08 & -0.97 & -0.55 \\
\hline $\boldsymbol{A}$ & 0.92 & 0.97 & 0.96 & 0.87 & 0.87 & 0.83 & 0.91 & 0.64 & 3.13 & 3.88 & 3.62 & 2.26 \\
\hline
\end{tabular}

